\title{
An In Vivo Characterization of Trophic Factor Production Following Neural Precursor Cell or Bone Marrow Stromal Cell Transplantation for Spinal Cord Injury
}

\author{
Gregory W.J. Hawryluk, ${ }^{1-3}$ Andrea Mothe, Jian Wang, ${ }^{1}$ Shelly Wang, ${ }^{1}$ \\ Charles Tator, ${ }^{1-3}$ and Michael G. Fehlings ${ }^{1-4}$
}

Cellular transplantation strategies for repairing the injured spinal cord have shown consistent benefit in preclinical models, and human clinical trials have begun. Interactions between transplanted cells and host tissue remain poorly understood. Trophic factor secretion is postulated a primary or supplementary mechanism of action for many transplanted cells, however, there is little direct evidence to support trophin production by transplanted cells in situ. In the present study, trophic factor expression was characterized in uninjured, injureduntreated, injured-treated with transplanted cells, and corresponding control tissue from the adult rat spinal cord. Candidate trophic factors were identified in a literature search, and primers were designed for these genes. We examined in vivo trophin expression in 3 paradigms involving transplantation of either brain or spinal cordderived neural precursor cells (NPCs) or bone marrow stromal cells (BMSCs). Injury without further treatment led to a significant elevation of nerve growth factor (NGF), leukemia inhibitory factor (LIF), insulin-like growth factor-1 (IGF-1), and transforming growth factor- $\beta 1$ (TGF- $\beta 1$ ), and lower expression of vascular endothelial growth factor isoform A (VEGF-A) and platelet-derived growth factor-A (PDGF- $A$ ). Transplantation of NPCs led to modest changes in trophin expression, and the co-administration of intrathecal trophins resulted in significant elevation of the neurotrophins, glial-derived neurotrophic factor (GDNF), LIF, and basic fibroblast growth factor (bFGF). BMSCs transplantation upregulated NGF, LIF, and IGF-1. NPCs isolated after transplantation into the injured spinal cord expressed the neurotrophins, ciliary neurotrophic factor (CNTF), epidermal growth factor $(E G F)$, and $b F G F$ at higher levels than host cord. These data show that trophin expression in the spinal cord is influenced by injury and cell transplantation, particularly when combined with intrathecal trophin infusion. Trophins may contribute to the benefits associated with cell-based repair strategies for spinal cord injury.

\section{Introduction}

$\mathrm{C}$ ELL-BASED REPAIR STRATEGIES for spinal cord injury (SCI) have shown consistent but modest benefit in experimental models [1-4]. Little is currently known about how transplanted cells lead to functional recovery after transplantation or how they interact with the host spinal cord [5]. A greater understanding of these effects may lead to strategies to augment functional recovery [6].

Trophic factor production has been postulated a primary or supplementary mechanism of action for transplanted cells, in particular where neuroprotective effects have been described and where benefit persists despite death of the transplanted cells [5,7-9]. Although alternate mechanisms such as environmental detoxification or provision of metabolic support could also explain these findings [10], neurotrophins and related trophic factors could underlie these beneficial effects, as they have been ascribed wide-ranging, repair-promoting effects within the CNS [5,11-13]. Trophic factors recruit and stimulate proliferation and differentiation of neural precursor cells (NPCs) [14]. They also have antiapoptotic effects [15] and enhance axonal regrowth [16], remyelination [17,18], and neuronal plasticity $[19,20]$. Since such effects have been noted after transplantation of NPCs and bone marrow stromal cells (BMSCs) [21-24], it is possible that both cell types could provide trophic support either by secreting trophins or by inducing trophin production by host cells. Currently there is little direct evidence to support

\footnotetext{
${ }^{1}$ Division of Genetics and Development, Krembil Neuroscience Center, Toronto Western Research Institute, University Health Network, Toronto, Canada.

${ }^{2}$ Institute of Medical Science and Neuroscience Program, University of Toronto, Toronto, Canada.

${ }^{3}$ Division of Neurosurgery, Department of Surgery, University of Toronto, Toronto, Canada.

${ }^{4}$ Spinal Program, Neural Repair and Regeneration, University Health Network, Toronto, Canada.
} 
this. Recently, we have found differences in trophic factor expression in NPCs and BMSCs in vitro in various culture conditions [25]. The purpose of the present study was to characterize the in vivo expression profile of trophic factors in the uninjured and injured rat spinal cord and after NPC and BMSC transplantation into the injured cord.

To determine whether trophins could contribute to recovery after SCI, we first characterized trophin production in the normal and injured spinal cord. We then examined trophin production after transplantation of either brain or spinal cord-derived NPCs or BMSCs into the injured rat spinal cord. These protocols are similar to those employed in trials involving human SCI patients [26-28]. In addition, we used fluorescence-activated cell sorting (FACS) to isolate exogenous cells after transplantation in one of these models, facilitating the characterization of a pure isolate of these cells. This is the first study that characterizes trophin expression in vivo after NPC and BMSC transplantation into the injured rat spinal cord, and in a pure population of exogenous cells isolated post-transplant. These results enhance our understanding of trophic factor expression after SCI and cell transplantation, which is important for the development of therapeutic strategies for SCI.

\section{Materials and Methods}

\section{General animal care and surgical procedures}

All animal work was conducted in accordance with the Canadian Council on Animal Care guidelines, and local institutional ethics approval was obtained for the experiments performed. Prophylactic preoperative amoxicillin-clavulinic acid was provided as infection prophylaxis. Animal surgeries were performed using sterile technique in conjunction with halothane or isofluorane anesthesia. Buprenorphine was administered postoperatively for analgesia. Animals were given food and water ad libitum, and their bladders were manually expressed thrice a day. Blinding to group assignment in all 3 transplant paradigms was maintained until statistical analysis was completed. Sample sizes employed are presented in Supplementary Table S1; Supplementary Data are available online at www.liebertonline .com/scd.

\section{Isolation of cellular substrates}

Spinal cord NPCs employed in transplant Paradigm 1 were isolated from the spinal cords of transgenic adult female Wistar rats expressing enhanced green fluorescent protein (eGFP) (Wistar-TgN(CAG-GFP)184ys) (YS Institute Inc.) [29]. The isolation of NPCs derived from the adult periventricular spinal cord was performed as previously described [30]. Cervical and thoracic spinal cord was excised under sterile conditions and washed in Dulbecco's phosphate-buffered saline supplemented with $30 \%$ glucose (Sigma-Aldrich) and 1\% penicillin/streptomycin (SigmaAldrich). The overlying meninges, blood vessels, and white matter were removed. Tissue from the periventricular region was then harvested. Dissected spinal cord tissue was enzymatically dissociated in a solution containing $0.01 \%$ papain and $0.01 \%$ DNase I for $1 \mathrm{~h}$ at $37^{\circ} \mathrm{C}$, and then mechanically dissociated into a cell suspension that was centrifuged using a discontinuous density gradient to remove cell membrane fragments. Cells were resuspended in Neurobasal-A medium (Gibco-Invitrogen) supplemented with B27 (GibcoInvitrogen), L-glutamine (Gibco-Invitrogen), penicillin/ streptomycin (Gibco-Invitrogen), $20 \mathrm{ng} / \mathrm{mL}$ each of epidermal growth factor (EGF) and basic fibroblast growth factor (bFGF) (Sigma-Aldrich), $2 \mu \mathrm{g} / \mathrm{mL}$ heparin (Sigma-Aldrich), and hormone mix as described [30]. Cells were plated in uncoated Nunc T25 culture flasks (VWR International), and the neurospheres generated were passaged weekly by mechanical dissociation in the serum-free medium just described.

To generate NPCs from adult mouse brains employed in transplant Paradigm 2, enhanced yellow fluorescent protein (eYFP)-bearing mice were killed by cervical dissociation, and brains were removed using the sterile technique. The subventricular zone of the forebrain was dissected as previously described [31]. To dissociate cells, isolated tissue was transferred to a $30 \mathrm{~mL}$ low calcium artificial cerebrospinal fluid enzyme solution containing $40 \mathrm{mg}$ of trypsin (Sigma), $20 \mathrm{mg}$ of hyaluronidase (Sigma), and $3.5 \mathrm{mg}$ of kynurenic acid (Sigma) for $1 \mathrm{~h}$ at $37^{\circ} \mathrm{C}$. Trypsin was then inactivated, and cells were mechanically dissociated by agitation with a Pasteur pipette. Cells were then transferred to uncoated T25 tissue culture flasks in $10 \mathrm{~mL}$ of serum-free medium containing $1 \mathrm{~mL}$ of DMEM/F-12, $0.2 \mathrm{~mL}$ of $30 \%$ glucose, $0.15 \mathrm{~mL}$ of $7.5 \% \mathrm{NaHCO}_{3}, 0.05 \mathrm{~mL}$ of $1 \mathrm{M}$ HEPES, $0.05 \mu \mathrm{g}$ of bFGF, $0.1 \mu \mathrm{g}$ of EGF, $1 \%$ L-glutamine (Gibco-Invitrogen), and 1\% penicillin/streptomycin (Sigma) for 7 days. The neurospheres generated were passaged weekly by mechanical dissociation in the same medium.

BMSCs employed in transplant Paradigm 3 were cultured as previously described [32,33]. Briefly, bone marrow was collected from the femurs, and the tibia of the eGFP transgenic rats just described $\left(\sim 40-50 \times 10^{7}\right.$ cells per rat) and resuspended in long-term bone marrow culture medium. The cells were incubated at $37^{\circ} \mathrm{C}$ in $5 \% \mathrm{CO}_{2}$. Cells were passaged after 2 weeks, and then every 5-7 days. Cells were characterized according to the methods recommended by Dominici et al. [34]. Using this protocol, we have previously shown that BMSCs show no evidence of differentiation in vitro into astrocytes, oligodendrocytes, or neurons [32,35].

\section{Transplantation paradigms}

Paradigm 1-adult spinal cord NPC transplantation. Adult female Wistar rats were subject to a $1 \mathrm{~min} 26 \mathrm{~g}$ clip compression injury [36] at the T8 bony level following a laminectomy from T8-9. One week later, 4 animals were randomized to transplantation with $2 \times 10^{5} \mathrm{P} 3$ or P4 adult spinal cord-derived NPCs, and 3 animals in the control group were injected with culture medium alone. Rats were anesthetized with inhalation of halothane, and the injury site was re-exposed. Five microliters of cells or media was injected at 2 intraspinal sites at the midline, $\sim 1 \mathrm{~mm}$ rostral, and caudal to the injury epicentre. Both groups were treated with daily doses of cyclosporin $(10 \mathrm{mg} / \mathrm{kg}$; Novartis, administered subcutaneously). Animals from this paradigm were sacrificed one week after experimental or control transplant. $1 \mathrm{~cm}$ of perilesional cord centered on the epicenter was then extracted from each animal for RNA isolation.

Paradigm 2-adult brain NPC xenotransplantation with trophin infusion. Adult female Wistar rats were subject to a $1 \mathrm{~min} 23 \mathrm{~g}$ clip compression injury [36] at the T7 bony level 
after a laminectomy from T6-8. Two weeks later, the animals were randomly assigned to one of 5 experimental groups, 3 of which were previously investigated by our group [31]. The Injured No Treatment group received no further treatment. For the other experimental groups, 'IS' denotes a 10 days course of minocycline $(50 \mathrm{mg} / \mathrm{kg}$; Sigma, administered intraperitoneally) and daily cyclosporin $(10 \mathrm{mg} / \mathrm{kg}$; Novartis, administered subcutaneously) both starting 2 days before control or cell transplantation. 'GF' denotes implantion of an osmotic mini-pump (Alzet model 1007D, primed overnight) delivering EGF ( $3 \mu \mathrm{g} / 100 \mu \mathrm{L}$; Sigma), bFGF ( $3 \mu \mathrm{g} /$ $100 \mu \mathrm{L}$; Sigma), and platelet-derived growth factor-A (PDGFA) $(1 \mu \mathrm{g} / 100 \mu \mathrm{L}$; Sigma) for 7 days at the time of cell or control transplantation. Distinct from our group's previous work, the catheter tip was placed $1 \mathrm{~cm}$ rostral to the epicenter to prevent dislodgement. Cellular and control transplantation was conducted at 4 intraspinal sites, $\sim 2 \mathrm{~mm}$ rostral, and caudal to the injury epicenter on both sides of the midline $(2 \mu \mathrm{L}$ each). Injured + GF/IS animals underwent sham transplantation with cell suspension media alone. Animals transplanted with NPCs received a total of $4 \times 10^{5}$ live cells. The Dead Cell + GF/IS group was transplanted with the same number of NPCs killed by 10 freeze-thaw cycles [37]. In this paradigm, at least 3 animals per group were employed in quantitative polymerase chain reaction (qPCR) and protein studies.

Animals from this paradigm were sacrificed 1 week after experimental or control transplant. One centimeter of perilesional spinal cord was then extracted from each animal for RNA and protein isolation. These segments were centered on the epicenter and spanned both rostral and caudal transplant sites. $1 \mathrm{~cm}$ of uninjured spinal cord tissue was also extracted from equivalent regions of uninjured rat spinal cord for both RNA and protein analyses to facilitate comparison.

Paradigm 3-adult BMSC transplantation via lumbar puncture and infusion. Adult female Wistar rats were subject to a $1 \mathrm{~min} 26 \mathrm{~g}$ clip compression injury [36] at the T8 bony level after a laminectomy from T8-9. One week later, animals were randomized to transplantation with $2 \times 10^{6}$ adult rat-derived BMSCs administered via lumbar puncture and the control group that was infused with vehicle [0.1M phosphatebuffered saline (PBS) and $0.2 \%$ bovine serum albumin (BSA)]. Rats were re-anesthetized as just described and placed prone. A longitudinal incision was made over the L3-5 spinous processes, and the skin was retracted as previously described [35]. A neonatal 25 gauge LP needle was advanced into the spinal canal at L3-4 or L4-5. Proper placement of the needle was determined by the presence of CSF in the hub of the needle. The CSF present in the needle hub was aspirated using a micropipette and $40 \mu \mathrm{L}$ containing $2 \times 10^{6}$ BMSC in $0.1 \mathrm{M}$ PBS and $0.2 \%$ BSA or vehicle alone was slowly injected into the intrathecal space [35]. Both groups were treated with daily doses of cyclosporin $(10 \mathrm{mg} /$ $\mathrm{kg}$; Novartis, administered subcutaneously). Animals from this paradigm were sacrificed one week after experimental or control transplant. $1 \mathrm{~cm}$ of perilesional cord centered on the epicenter was then extracted from each animal for RNA isolation. To characterize delivery of transplanted cells to the uninjured spinal cord as well as a potential trophin influence in uninjured regions, control tissue was also extracted from all animals from a $1 \mathrm{~cm}$ region just above the conus medullaris and subject to the same analysis.

\section{Fluorescence-activated cell sorting}

$1 \mathrm{~cm}$ spinal cord segments centered on the injury epicenter from NPC + GF/IS animals (Paradigm 2) were extracted and then incubated in $0.1 \%$ collagenase for $1 \mathrm{~h}$ at $37^{\circ} \mathrm{C}$. After trituration, digested tissue was re-suspended in medium containing $1 \times$ HBSS (Ca and $\mathrm{Mg}$ free), 10 mM HEPES $\mathrm{pH} 7.2$, $2 \%$ fetal bovine serum, and $10 \mathrm{mM} \mathrm{NaN}_{3}$ and passed through a $70 \mu \mathrm{m}$ cell strainer. Cells were then re-suspended at a concentration of 5-10 million cells $/ \mathrm{mL}$, and incubated with propidium iodide $(10 \mu \mathrm{g} / \mathrm{mL})$ for $30 \mathrm{~min}$ at room temperature to facilitate exclusion of dead cells. A Becton Dickinson FACS Aria 13-colour cell sorter was employed to isolate eYFP + and eYFP- cells after calibration with positive and negative controls. Samples from 3 animals were pooled and diluted to the minimum volume required to perform qPCR in triplicate with all primer pairs.

\section{RNA isolation and cDNA synthesis}

For RNA isolation, RNaseZAP ${ }^{\circledR}$ (Gibco-Invitrogen) was used to treat all tools, gloves, and working areas employed. Cultured cells were collected and homogenized in Trizol ${ }^{\circledR}$ (Gibco-Invitrogen). After extraction with chloroform, removal of the aqueous layer, precipitation with isopropyl alcohol, and a wash with $75 \%$ ethanol, the RNA pellets were resuspended in RNase free water. Spectroscopy was then performed using a NanoDrop 1000 Spectrophotometer (Thermo Fisher Scientific) to ensure successful RNA harvest and determine its concentration. cDNA was subsequently synthesized using Superscript II reverse transcriptase (GibcoInvitrogen) and Oligo(dT) ${ }_{12-18}$ primers (Gibco-Invitrogen).

\section{qPCR analysis}

Candidate trophic factors were identified in a literature review. Primers were designed for factors consistently found to be produced by neural cells, upregulated at the epicenter of a CNS injury, or of demonstrated benefit in CNS repair [12,38-46]. Primers were designed for nerve growth factor (NGF), brain-derived neurotrophic factor (BDNF), neurotrophin-3 (NT-3), neurotrophin-4/5 (NT-4/5), glialderived neurotrophic factor (GDNF), ciliary neurotrophic factor (CNTF), PDGF-A, EGF, bFGF, leukemia inhibitory factor $(L I F)$, insulin-like growth factor-1 (IGF-1), glial growth factor 2 (GGF2), transforming growth factor- $\beta 1$ (TGF- $\beta 1$ ), and vascular endothelial growth factor isoform A (VEGF-A). Primers were also designed for the housekeeping gene glyceraldehyde 3-phosphate dehydrogenase (GAPDH), which has been employed in trophin studies by several other groups [47-49]. Primers were designed with careful consideration of the structure of each gene ensuring the sequence was common to all active isoforms or unique to specific isoforms where indicated. The most highly conserved sequence in these regions was entered into PrimerQuest software (www.idtdna.com) and BLAST analysis of primer sequences was employed to ensure specificity. Primer sequences are presented in Supplementary Table S2. Most primer sequences have been previously published [25].

With the exception of specimens obtained from FACS sorting, cDNA template was diluted to $3 \mathrm{ng} / \mu \mathrm{L}$. qPCR reactions were performed using SYBR Green chemistry and an ABI $7900 \mathrm{HT}$ fast real-time PCR thermal cycler (Applied 
Biosystems). Absolute quantitation was performed, and all assays were performed in at least triplicate. Analysis was performed using SDS 2.3 software.

\section{Western blotting}

In Paradigm 2, $1 \mathrm{~cm}$ of perilesional spinal cord tissue centered on the epicenter was extracted from distinct animals in Ringer's Lactate maintained at $4^{\circ} \mathrm{C}$. Protein samples were prepared after determination of protein concentration with the Lowry Method. Samples were then run on $12 \%$ polyacrylamide gels and then transferred onto nitrocellulose overnight. Coomassie Blue staining was employed to verify the presence of protein. Confirmatory western blotting for VEGF-A was performed using an antibody specific for the 'A' isoform (Santa Cruz; sc-152, 1:200 dilution incubated at $4^{\circ} \mathrm{C}$ overnight). Confirmatory western blotting for BNDF was also performed (Santa Cruz, 1:500 dilution incubated at $4^{\circ} \mathrm{C}$ overnight). Normalization was performed to $\beta$-actin (Chemicon; MAB1501R, 1:400 dilution incubated at $4^{\circ} \mathrm{C}$ overnight). Anti-mouse-HRP conjugated secondary antibody was subsequently employed for $1 \mathrm{~h}$ at room temperature (Sigma; A-3682, 1:2,000). Images were generated for densitometry measurements using a Fluor-S Multilmager (BioRad), and measurements were made using Quantity One software (Bio-Rad, version 4.2.1). Alternate normalization to GAPDH (Sigma; G8795, 1:7,000) provided equivalent results.

\section{Statistical analysis}

SAS 9.2 software was used for statistical analysis. Results were analyzed with analysis of variance as a first step in all analyses and when significant at the 0.05 level, subsequent inter-group comparisons were made with a conservative Bonferroni adjustment for multiple comparisons.

\section{Results}

\section{Trophin expression in the uninjured lower thoracic spinal cord}

Figure 1A demonstrates that the uninjured lower thoracic spinal cord expresses detectable levels of all assayed trophins including NGF, BDNF, NT-3, NT-4/5, GDNF, CNTF, PDGF-A, EGF, bFGF, LIF, IGF-1, GGF2, TGF- $\beta 1$, and VEGF-A. The expression level varied greatly among the various factors when compared with expression of the house-keeping gene $G A P D H$. The neurotrophins, GDNF, and LIF were expressed at the lowest levels. Only CNTF, PDGF-A, and IGF-1 were expressed at levels higher than GAPDH.

\section{$\mathrm{SCl}$ influences trophin expression}

In a comparison of trophin expression in equivalent segments of injured (Injured No Treatment animals from Paradigm 2) and uninjured lower thoracic spinal cord in distinct animals 3 weeks after SCI, qPCR found significantly elevated expression of NGF, LIF, IGF-1, and TGF- $\beta 1$ (Fig. 1B). Expression of PDGF-A and VEGF-A was significantly reduced.

In control animals from Paradigm 3, a similar comparison was made. Here, injured regions of the spinal cord were compared with caudal uninjured regions of the same spinal cords 2 week postinjury in animals treated with cyclosporin.
Figure $1 \mathrm{C}$ shows very similar results to the aforementioned comparison of injured and uninjured tissue at 3 week posttransplant. Unlike the previous comparison, however, here the injured tissue demonstrated significant upregulation of PDGF-A, significant downregulation of GGF2, and no change in VEGF-A expression.

\section{NPC transplantation alone has modest effects on trophin expression}

In Paradigm 1, a simple NPC transplantation protocol in which both NPC transplanted and control transplanted rats were treated with cyclosporin, trophin expression was compared in the region of the epicenter. In this model, all 4 animals transplanted with NPCs expressed detectable eGFP levels indicating successful transplantation (Fig. 2A). NPC transplantation was associated with a significant increase in CNTF and IGF- 1 as well as significant decreases in BDNF and TGF- $\beta 1$ (Fig. 2B). The magnitude of these differences is small and of uncertain biological significance.

\section{NPC transplantation and trophin infusion is associated with a synergistic increase in trophin expression}

Trophin expression in perilesional tissue was also assessed in a distinct combinatorial transplantation protocol (Paradigm 2). NPC transplantation combined with perilesional trophin infusion was associated with a significant increase in the expression of NGF, BDNF, NT-3, NT-4/5, GDNF, LIF, and $b F G F$ (Fig. 3). Western blotting was performed for BDNF and VEGF-A, both of which demonstrated a close match between protein production and expression data (Fig. 4).

The effect of NPC transplantation in combination with pharmacotherapy and trophin infusion is distinct from the administration of either alone. In this transplant paradigm, trophin infusion and pharmacotherapy alone was associated with a significant downregulation of EGF, bFGF, IGF-1, TGF$\beta 1$, and $V E G F-A$, while NPC transplantation and pharmacotherapy without trophin infusion was associated with significant downregulation of only IGF-1 and TGF- $\beta 1$. A comparison of NPC + GF/IS and NPC + IS only groups suggests that the addition of a trophin pump is associated with a significant increase in NGF, NT-3, GDNF, and LIF with a significant decrease in PDGF.

In this paradigm, eYFP expression indicated successful transplantation of all 6 animals with NPCs (Supplementary Fig. S1). Trophin pump implantation did not increase the number of surviving NPCs. eYFP expression in the NPC + GF/IS group was $0.82 \%$ that of the pure $e Y F P+$ FACS isolate and in the NPC + IS only group it was $2.22 \%$. This suggests that the transplanted NPCs comprised $<3 \%$ of all cells within the harvested region of the spinal cord.

\section{NPCs express trophins after transplantation}

FACS was employed to determine whether the aforementioned expression changes were attributable to host spinal cord or transplanted cells (Supplementary Fig. S1). In the 3 transplanted cords analyzed, the number of eYFP+ cells isolated ranged from 662 to 117,223 corresponding to $0.0037 \%-2.9 \%$ of cells in the harvested region, which is very 

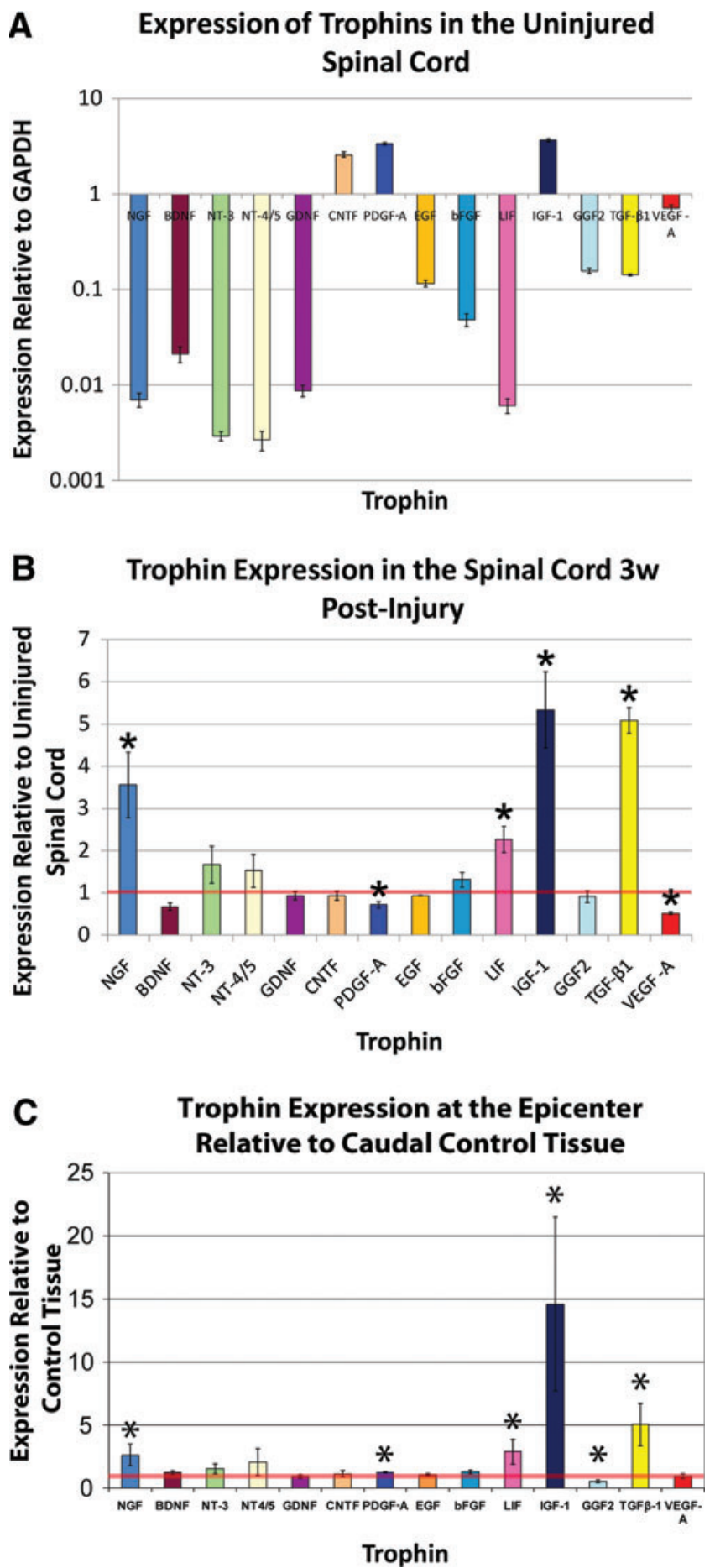

FIG. 1. (A) Trophin $\mathrm{qPCR}$ data is presented for $1 \mathrm{~cm}$ homogenates of the uninjured lower thoracic spinal cord. The values plotted represent average values for 3 animals, with specimens analyzed in quadruplicate for each animal. Values are presented on a logarithmic scale. All assayed trophic factors were detected. Only CNTF, PDGF, and IGF-1 are expressed at a higher level than the housekeeping gene GAPDH. (B) Trophin expression in the Injured No Treatment group (Paradigm 2) 3 weeks post-injury is plotted after normalization to the uninjured values shown in (A), denoted here by the horizontal red line. The values plotted represent average values for 3 animals, with specimens analyzed in quadruplicate for each animal. NGF, $L I F, I G F-1$, and TGF- $\beta 1$ are significantly elevated relative to uninjured values, while PDGF and VEGF- $A$ levels are significantly decreased. (C) In control animals from Paradigm 3, trophin expression at the epicenter was compared with a caudal control region, the latter denoted by the horizontal red line. The values plotted represent average values for 3 animals, with specimens analyzed in triplicate for each animal. NGF, PDGF, LIF, IGF-1, and TGF- $\beta 1$ are significantly elevated relative to uninjured values, while GGF2 levels are significantly decreased. *denotes $P<0.05$. NGF, nerve growth factor; $L I F$, leukemia inhibitory factor; IGF-1, insulin-like growth factor-1; TGF- $\beta 1$, transforming growth factor- $\beta 1$; CNTF, ciliary neurotrophic factor; VEGF-A, vascular endothelial growth factor isoform A; GAPDH, glyceraldehyde 3-phosphate dehydrogenase; PDGF$A$, platelet-derived growth factor-A; GGF2, glial growth factor 2; qPCR, quantitative polymerase chain reaction. Color images available online at www.liebertonline.com/scd 
A

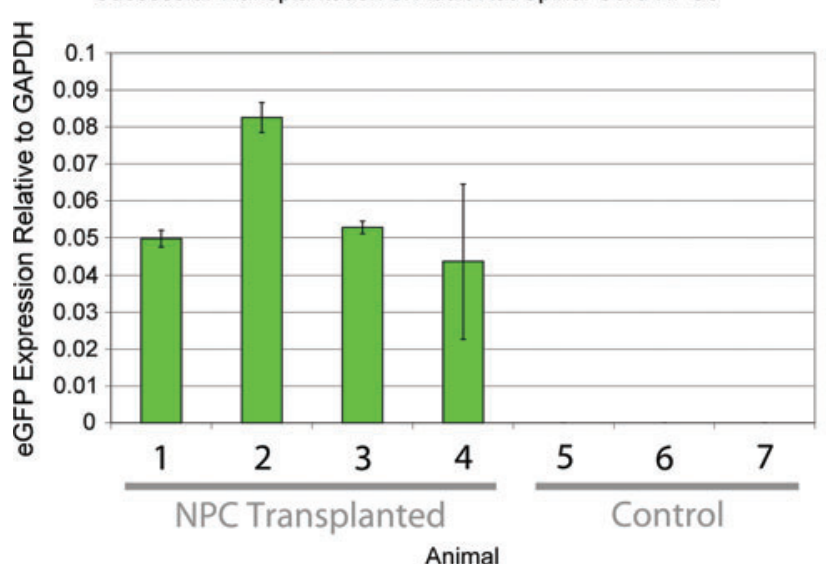

B Trophin Expression Following Adult Spinal Neural Precursor Cell Transplantation

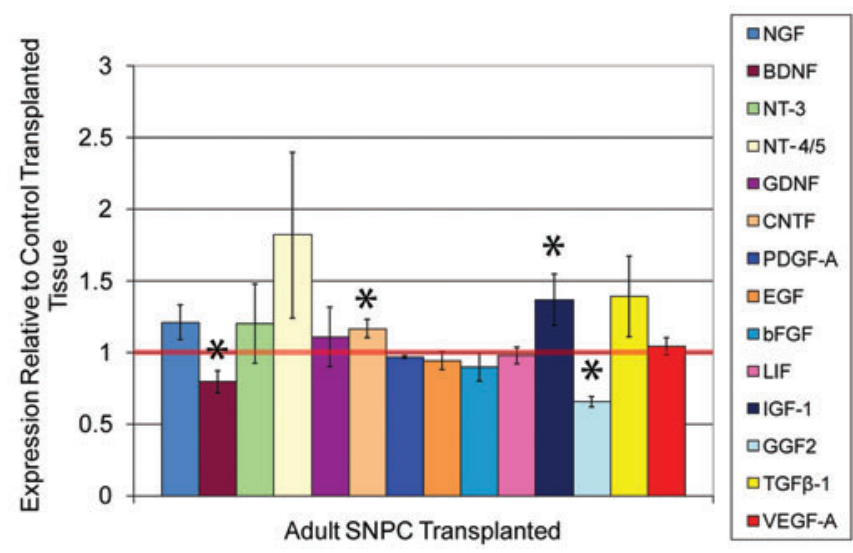

FIG. 2. (A) eGFP expression was noted in all 4 adult spinal cord NPC transplanted cords from Paradigm 1. No expression was noted in the 3 control cords, indicating that primers for eGFP is specific. (B) Trophin expression levels in lower thoracic spinal cord transplanted with NPCs from 4 animals is plotted relative to control transplanted tissue from 3 animals with the latter denoted by the horizontal red line. qPCR reactions were performed in triplicate for each animal. Adult spinal cord NPC transplanted cords had significantly higher levels of CNTF and IGF-1 and significantly lower levels of BDNF and GGF2. Other differences were not significant. ${ }^{*}$ denotes $P<0.05$. NPC, neural precursor cell; BDNF, brain-derived neurotrophic factor; $e G F P$, enhanced green fluorescent protein. Color images available online at www.liebertonline.com/scd

consistent with the estimate calculated based on eYFP expression as just reported.

qPCR for trophin expression performed on eYFP+ and eYFP-FACS specimens found that the $e Y F P+$ NPC-derived exogenous cells expressed detectable levels of all neurotrophins, CNTF, EGF, PDGF-A, and TGF- $\beta 1$ and that the transplanted cells expressed higher levels of all 4 neurotrophins, CNTF, bFGF, and EGF than eYFP host cord cells. Although the result for CNTF approached statistical significance $(P=0.0543)$, all statistical comparisons were not significant. Despite pooling the RNA obtained from 3 animals for this assay, trophin expression in these samples was near the limit of detection and subject to high variability necessitating careful interpretation.

\section{BMSC transplantation upregulates several trophins}

Of the 4 animals transplanted intrathecally with eGFP+ BMSCs via lumbar puncture, eGFP expression was detected in only 3 of the animals. The fourth was, thus, excluded from subsequent qPCR analysis (Supplementary Table S1). In all 3 successfully transplanted animals, higher eGFP expression was noted at the epicenter than at the caudal control region (Fig. 5). Intrathecal administration of BMSCs was associated with significant upregulation of NGF, LIF, and IGF-1 at the epicenter (Fig. 5) as well as a significant reduction in PDGFA. BMSC transplantation did not lead to significant expression changes in the caudal control region, though BMSCs were detected there based on positive eGFP expression.

\section{Cellular transplantation for $\mathrm{SCl}$ upregulates expression of inflammatory mediators}

Tissue subject to qPCR from all 3 transplant paradigms was also analyzed with regard to expression of the inflammatory mediators $I L-1 \beta, I L-6$, and TNF- $\alpha$ (Fig. 6). In all 3 cellular transplantation paradigms, transplanted cells ex- pressed these inflammatory mediators at higher levels than control tissue. The increase in all 3 mediators reached significance on post-hoc testing for the NPC + GF/IS group in Paradigm 2. In this paradigm, NPC transplantation alone (NPC + IS only) was associated with lower levels of inflammatory mediator expression than an injured untreated SCI when NPCs were administered along with the immunosuppressant drugs minocycline and cyclosporin. In Paradigm $3, I L-1 \beta$ was significantly increased in the region of the epicenter by BMSC transplantation.

\section{Discussion}

Currently, there is little information about trophic factor expression in the normal and injured spinal cord, and even less is known about how cellular transplantation alters this expression. To date, the present study is the most extensive characterization of trophin expression in normal, injured, and transplanted spinal cord. Analysis of 3 distinct cellular transplantation paradigms provides valuable insights into how trophins could contribute to neural repair in this novel therapeutic strategy. Within each paradigm, strong conclusions can be made with regard to how experimental variables influence trophin expression; however, comparisons between paradigms should be cautiously made, as numerous confounds prevent similarly strong conclusions. To our knowledge, this study is also the first thorough characterization of a pure population of exogenous cells isolated posttransplant. Our findings suggest that trophins are poised to contribute to neural recovery after cellular transplantation for SCI; for NPCs, this was particularly true when transplantation was combined with trophin infusion in the intrathecal space.

Trophin expression is a valuable means of characterizing trophin production. $\mathrm{qPCR}$ is highly sensitive and able to detect minute levels of transcript inherent to trophin 
proteins that have biological activities at picomolar concentrations. Although one cannot be certain whether these levels of expression reflect protein levels, protein assays are not inherently superior for trophins, as Okragly et al. have demonstrated inaccuracies of protein assays related to tissue- and species-specific sequestration of trophin proteins [50].
Trophin expression in the adult, uninjured spinal cord

To date, few studies have characterized trophin expression in the normal and injured spinal cord. The expression of a few trophic factors has been studied, and many report data examining only one factor. The most commonly examined
A

\section{Trophin Expression in Experimental Groups} and FACS Specimens

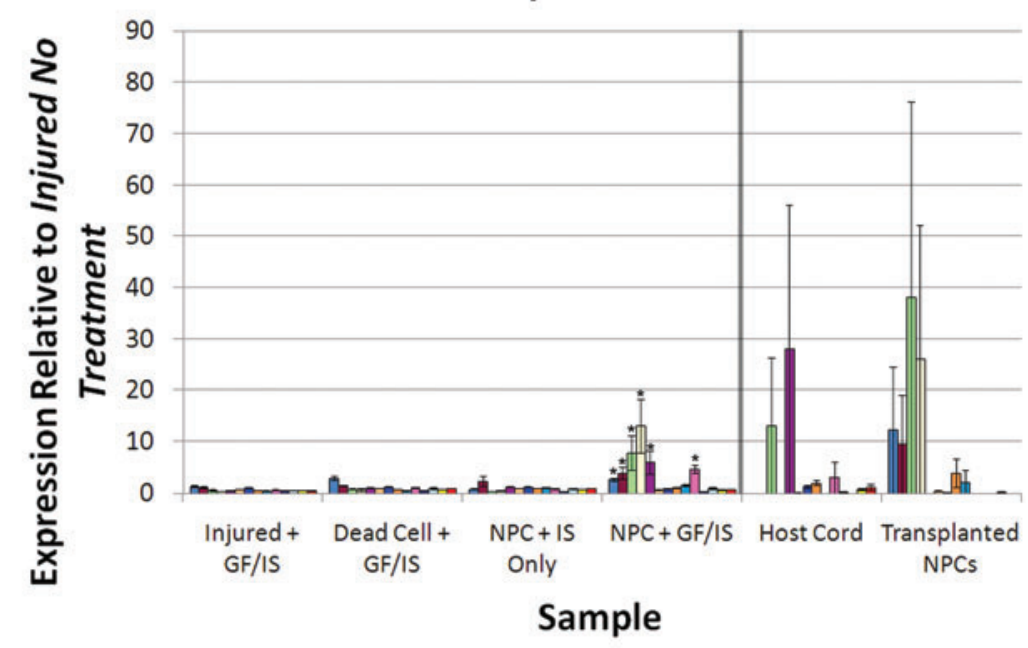

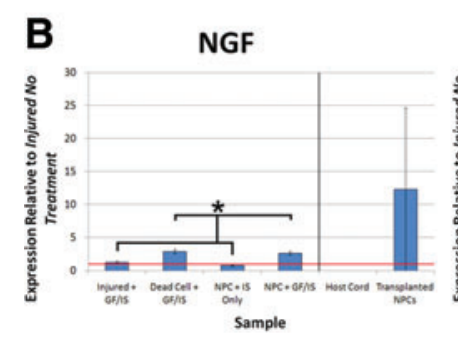

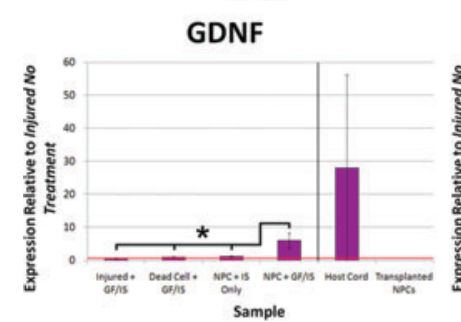

bFGF

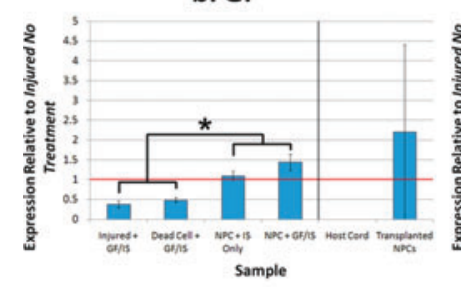

BDNF

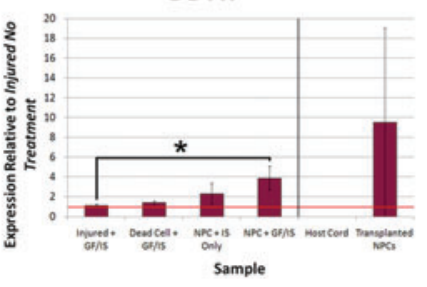

CNTF

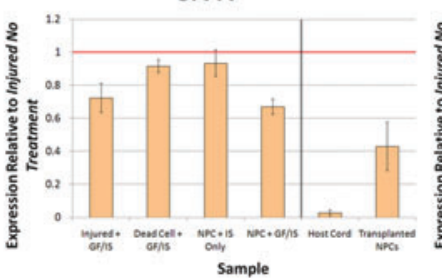

LIF

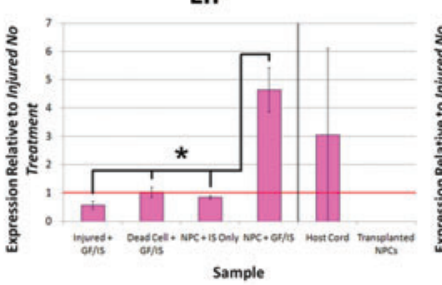

TGF- $\beta 1$

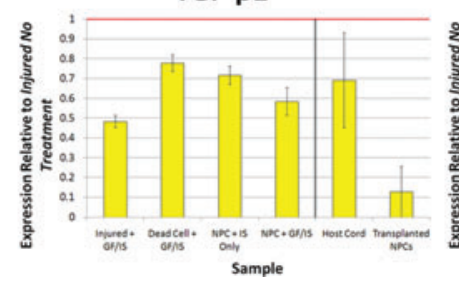

NT-3

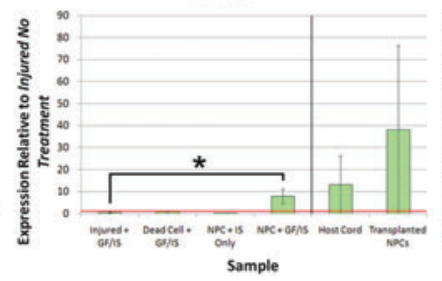

PDGF-A

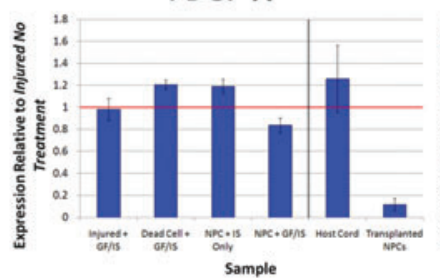

IGF-1

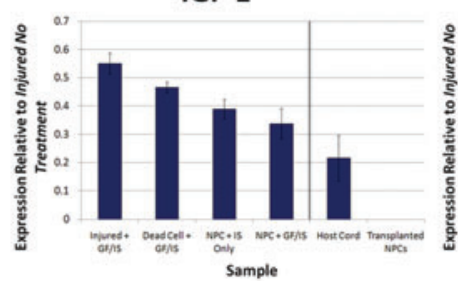

VEGF-A

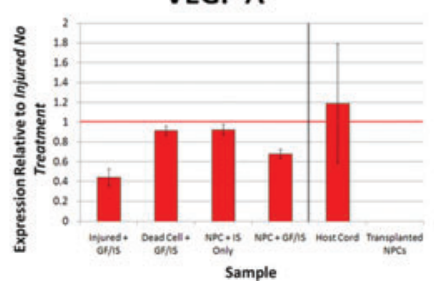

NT-4/5

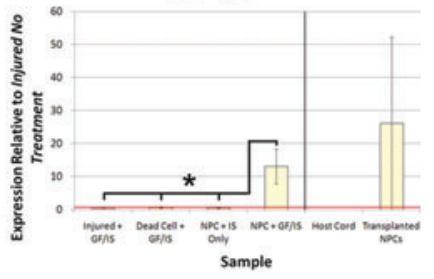

EGF

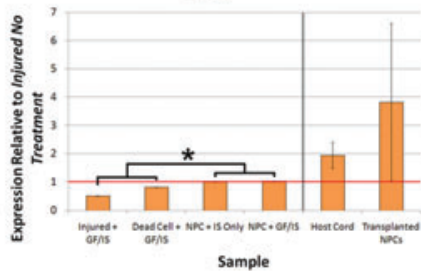

GGF2

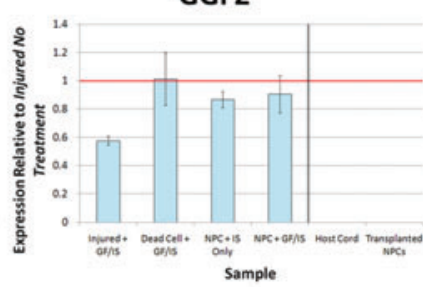


trophins include NGF, BDNF, and NT-3 [12,51-67]. However, there is very little information regarding the expression of other trophic factors including $b F G F, G D N F, C N T F, L I F$, and TGF- $\beta 1[12,13,48,49,52,62,68]$. Therefore, the present study greatly expands knowledge of trophin production in the normal and injured spinal cord.

We found that all assayed trophins were expressed in the uninjured rat spinal cord. However, many of the factors were expressed at low levels relative to GAPDH. This low level of neurotrophin expression is in accordance with low levels reported by others in the adult spinal cord [52]. For example, Dougherty et al. demonstrated low levels of BDNF and NT-3 in astrocytes, oligodendrocytes, and microglia/macrophages in the normal spinal cord with immunohistochemical analysis [51].

\section{Trophin expression in the injured spinal cord}

Trophin levels after injury may play an important role in the normal reparative processes that follow an SCI. Marked upregulation of trophins was observed after injury to the peripheral nervous system, as compared with more limited upregulation after injury to the CNS-which has been postulated to account, at least in part, for the marked difference in their regenerative potential [12]. Similarly, trophin levels are reportedly lower in the injured spinal cords of adults as compared with neonatal animals, and it has likewise been postulated to at least partially explain the discrepancy in agerelated regenerative responses [48].

To date, studies have reported highly variable findings related to trophin expression after SCI, likely resulting from varied injury models, injury severity, time points examined, species employed, and differences in tissue sampling and trophin assays $[12,58,62]$. Only a few studies have explored trophin expression more than a week after injury as we have done in the present study $[48,56]$. Most studies have shown upregulation of trophins after SCI [12,13,48,51,52,54,56, 58-60,62,63,65-68], whereas others have reported a decrease in trophin levels after injury $[48,59,61,62,66]$, or no change $[48,52,57,58,64]$. We found an upregulation of NGF, LIF, IGF1 , and TGF- $\beta 1$ expression after injury in both models of Paradigms 2 and 3, suggesting that there is a robust trophic factor response in the weeks after compressive SCI. Indeed, NGF production is upregulated by the inflammatory response, which is well described after SCI [67,69-71]. NGF may have both beneficial and deleterious roles in this context; although it stimulates survival of sympathetic and sensory neurons, it can also cause neuropathic pain, and its pro-form induces cell death [72]. LIF has been shown to be upregulated after CNS injury $[68,73]$. Although it induces cell survival $[68,74-78]$ and corticospinal tract growth [44], LIF increases astrogliosis [79-82] and increases the inflammatory response [68]. LIF was also shown to increase the production of IGF-1 by activated microglia and macrophages [78] and, thus, it is noteworthy that IGF-1 was also consistently upregulated in our study. IGF-1 has been demonstrated to preserve neurons after SCI $[83,84]$ and has been shown to increase the outgrowth of corticospinal axons [85]. TGF- $\beta 1$ is an anti-inflammatory cytokine known to downregulate nitric oxide synthase $[49,86]$. TGF- $\beta 1$ was shown to protect neurons from loss after an ex vivo model of CNS injury [87] and improved functional outcome after TGF- $\beta 1$ infusion at the site of SCI [86]. This may relate to the ability of TGF- $\beta 1$ to potentiate the effects of $b F G F, C N T F$ and GDNF [88].

The differences noted for PDGF- $A$ and VEGF- $A$ expression between transplantation Paradigms 2 and 3 may be related to differences in the time from injury, differential presence of minocycline, cyclosporin, or differences inherent to distinct regions of spinal cord. Indeed, within the 3 paradigms, care was taken to compare equivalent regions of spinal cord, as there is a suggestion that trophin expression may vary with spinal cord level [62]. Nonetheless, the suggestion that VEGF-A may be downregulated in injured CNS tissue provides impetus for angiogenic therapeutic strategies for SCI [89].

\section{Trophins could contribute to the benefits associated with cellular transplantation}

Numerous groups have reported tissue sparing associated with cellular transplantation for SCI. Although mechanisms other than trophin secretion could account for this effect [10], it does raise the possibility that trophin secretion could be an important mechanism by which transplanted cells act. Interestingly, Keirstead's group have reported tissue sparing after the transplantation of both human oligodendrocyte progenitor cells (OPCs) and human motor neuron progenitor cells $[21,90]$. When the latter cells were transplanted, they also found sprouting of endogenous seritonergic projections

FIG. 3. Trophin infusion and NPC transplantation is associated with a synergistic increase in trophin expression. (A) Trophin expression in cord homogenates and FACS specimens from Paradigm 2 are shown after normalization to Injured No Treatment values. (B) Data presented in (A) is re-plotted for each trophin individually. Here, horizontal red lines denote Injured No Treatment values. Analysis of variance showed significant differences for $N G F(P<0.0001), B D N F(P=0.0243)$, NT-3 $(P=0.0008)$, NT-4/5 $(P=0.0120)$, GDNF $(P=0.0007)$, EGF $(P<0.0001), b F G F(P<0.0001)$, and LIF $(P<0.0001)$. For NGF, post-hoc testing found that expression in the Dead Cell + GF/IS and NPC + GF/IS groups was significantly greater than that in the Injured No Treatment, Injured + GF/IS, and NPC + IS Only groups. For NT-3, GDNF, and LIF expression in the NPC + GF/IS group was significantly greater than all other groups. For BDNF and NT-4/5 expression in the NPC + GF/IS group was significantly greater than in the Injured No Treatment and Injured + GF/IS groups. For EGF and bFGF expression in the Injured No Treatment, NPC + IS Only, and NPC + GF/IS groups was significantly greater than in the Injured + GF/IS and Dead Cell + GF/IS groups. FACS expression data was analyzed separately and showed no significant differences.

Sample sizes: Injured No Treatment $n=3$, Injured + GF/IS $n=3$, Dead Cell + GF/IS $n=4, N P C+I S$ Only $n=3, N P C+$ GF/IS $n=3$, FACS $n=3$; qPCR was performed in quadruplicate. *denotes $P<0.05$. NT-3, neurotrophin-3; NT-4/5, neurotrophin-4/ 5 ; bFGF, basic fibroblast growth factor; EGF, epidermal growth factor; GDNF, glial-derived neurotrophic factor; FACS, fluorescent-activated cell sorting. Color images available online at www.liebertonline.com/scd 


\section{A VEGF-A Expression in Experimental Groups 1w Post-Transplant}

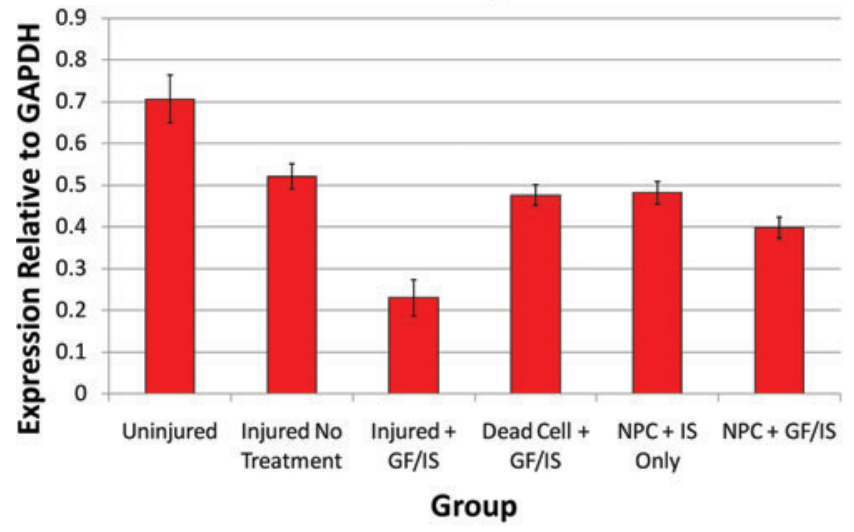

B BDNF Expression in Experimental Groups 1w Post-Transplant

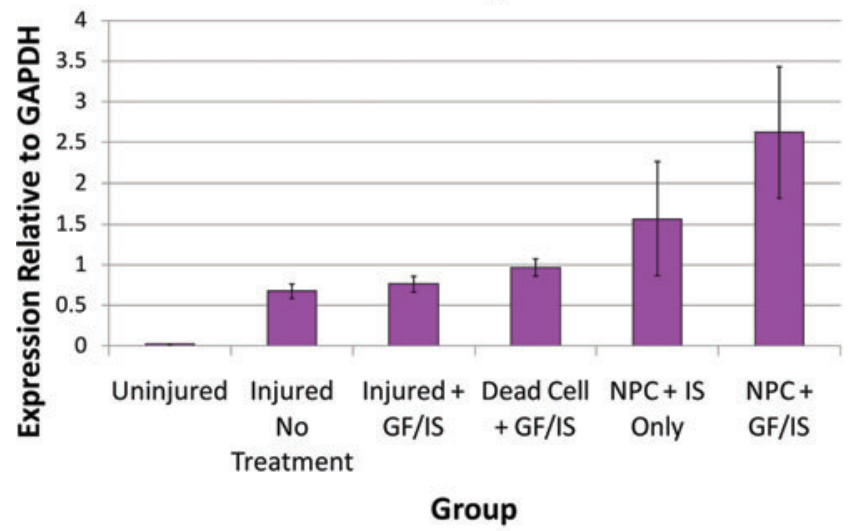

VEGF-A Protein In Experimental Groups 1w Post-Transplant

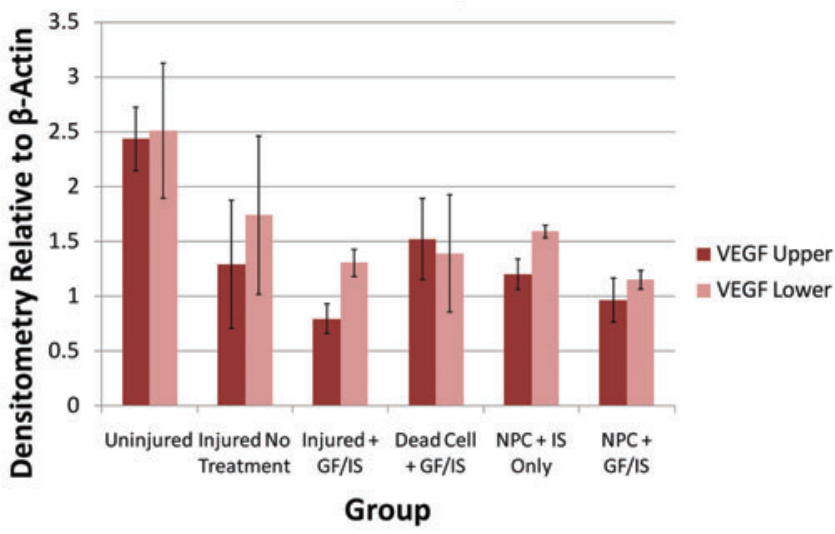

BDNF Protein In Experimental Groups 1w Post-Transplant

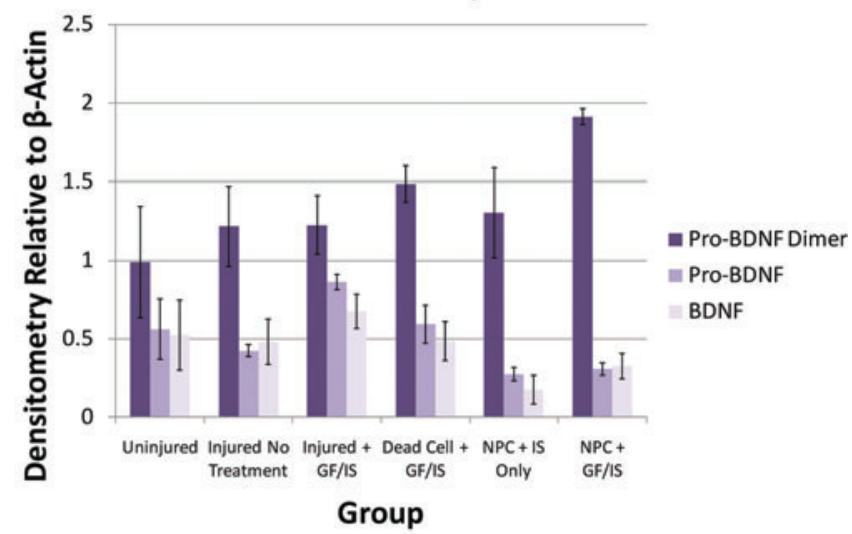

C
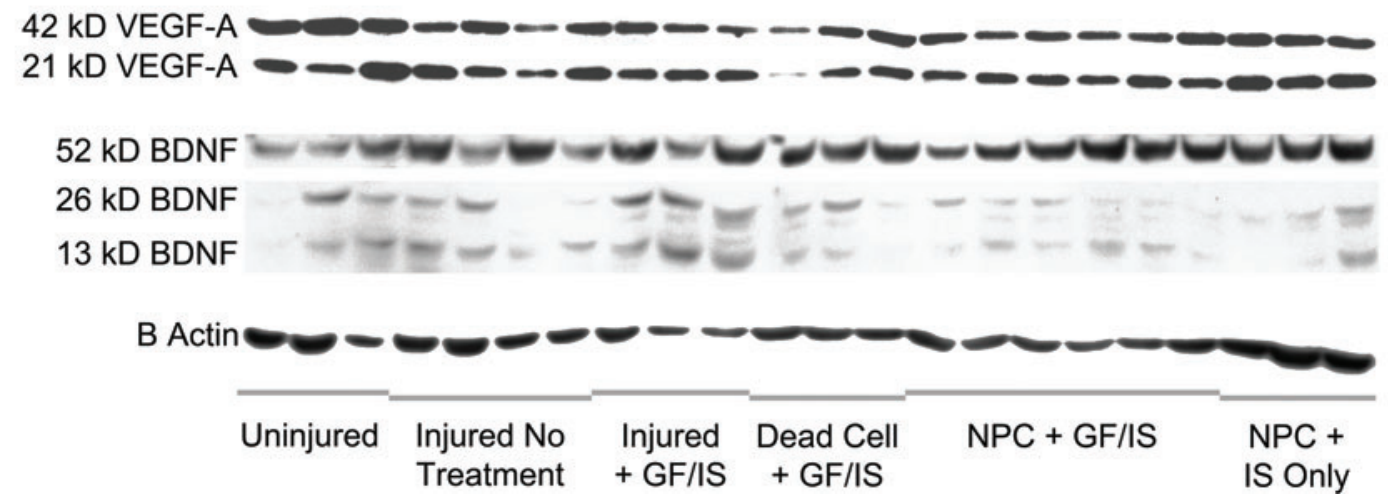

FIG. 4. Trophin expression and protein quantitation for VEGF-A and BDNF are concordant. Concordant RNA (left) and protein (right) quantitation is shown for $V E G F(\mathbf{A})$ and BDNF (B), all analyzed 1 week post-transplant. The expression data have been re-plotted from Figure 3 with an alternate normalization to GAPDH alone. Bands used for densitometry measurements for 22 animals among the 6 experimental groups are shown in (C).

Sample sizes: Uninjured qPCR 3, Western Blot $n=3$; Injured No Treatment qPCR $n=3$, Western Blot $n=4$; Injured + GF/IS qPCR $n=3$ Western Blot $n=3$, Dead Cell + GF/IS qPCR $n=4$, Western Blot $n=3, N P C+$ IS Only qPCR $n=3$, Western Blot $n=3$, NPC + GF/IS $q P C R \quad n=3$ Western Blot $n=6$. qPCR was performed in quadruplicate. Color images available online at www.liebertonline.com/scd

and enhanced survival of endogenous neurons [90]. Bambakidis et al. have also reported white matter sparing associated with the transplantation of OPCs [22]. This raises the possibility that trophins produced by transplanted cells, or by the host in response to transplanted cells, could contribute to the functional benefits associated with cellular transplantation. However, rather than characterizing trophin production in vivo, numerous studies suggest that transplanted cells could have a trophic effect based on extrapolation of in vitro findings [21,90-93]. 
A

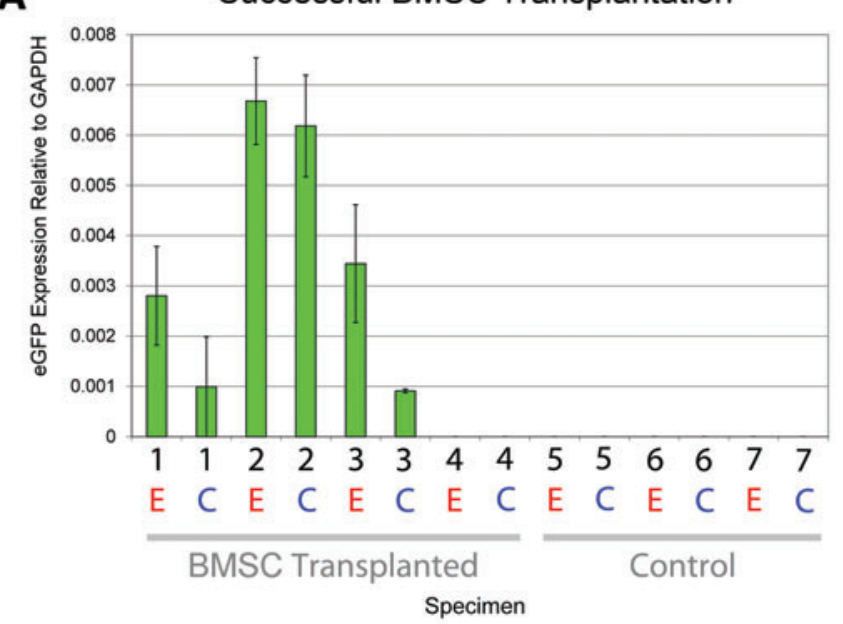

B Trophin Expression in a BMSC Transplantation Paradigm

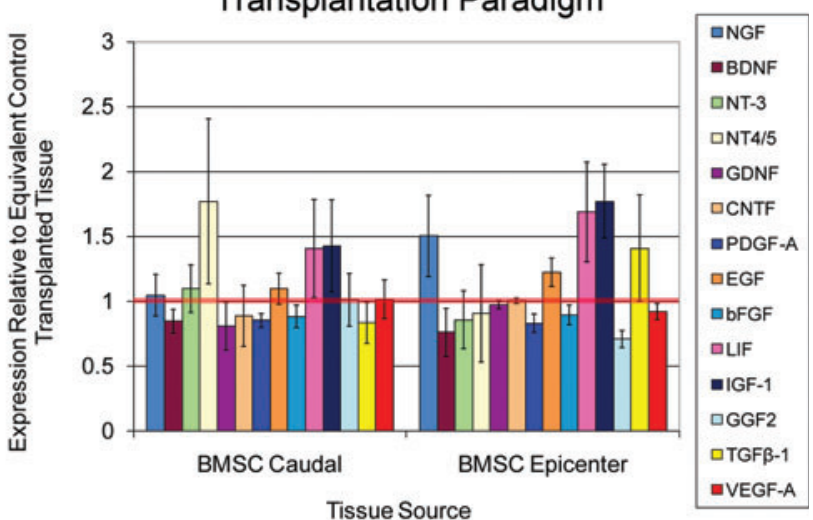

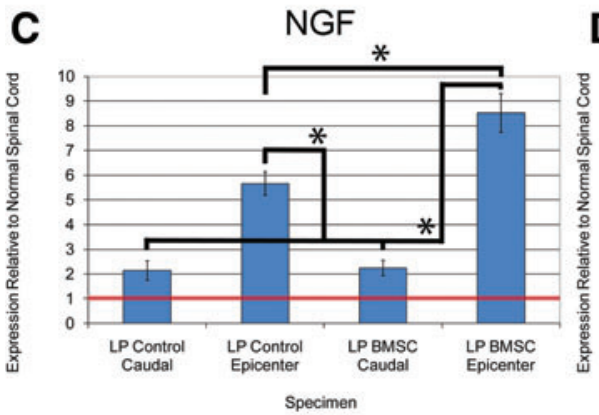

$\mathbf{F}$

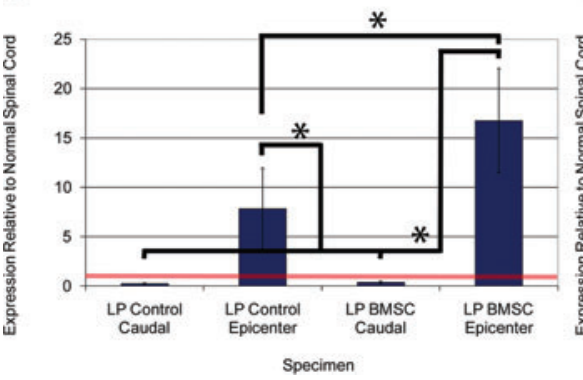

D

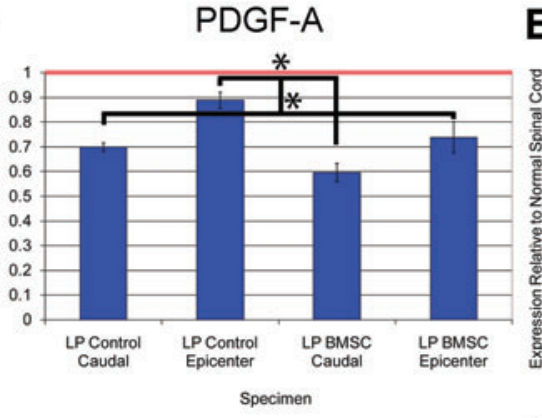

G

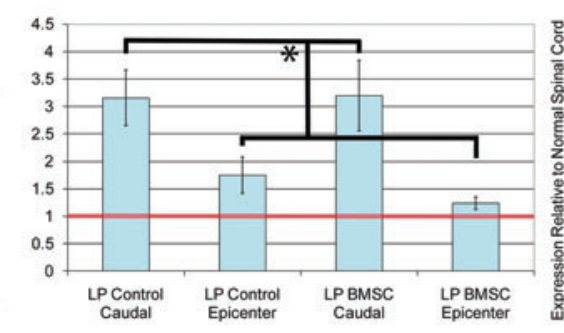

Specimen
E

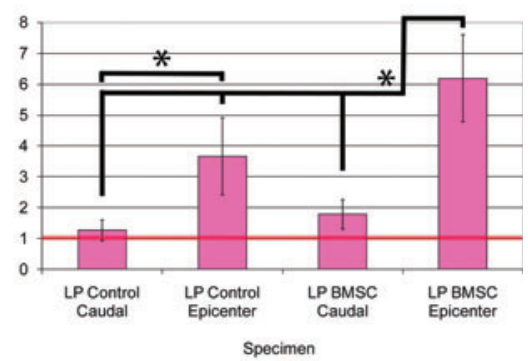

H

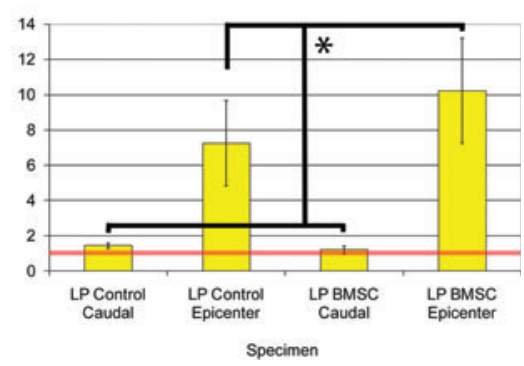

FIG. 5. BMSC transplantation upregulates several trophins. (A) On the x-axis, the numbers denote experimental animals, while $\mathbf{E}$ (red) and $\mathbf{C}$ (blue) denote epicenter and caudal regions of spinal cords from these animals. eGFP expression was noted in 3 of 4 BMSC transplanted cords; the unsuccessfully transplanted cord was excluded from further analysis. Higher $e G F P$ expression was found at the epicenter in all cases. No eGFP expression was noted in the 3 control transplanted cords. (B) BMSC transplanted spinal cord tissue from the epicenter (right) and caudal control region (left) is plotted relative to values from control tissue from equivalent regions with the latter denoted by the horizontal red line. $(\mathbf{C}-\mathbf{H})$ Values from (B) are re-plotted. BMSCs administered by lumbar puncture led to significantly higher levels of NGF, LIF, IGF-1, and TGF- $\beta 1$ at the epicenter in comparison to those treated with saline infusion. All qPCR reactions were performed in triplicate. ${ }^{*}$ denotes $P<0.05$. LP reflects administration of BMSCs via lumbar puncture; caudal refers to a control region of uninjured tissue caudal to the epicenter. BMSC, bone marrow stromal cell; LP, lumbar puncture. Color images available online at www.liebertonline.com/scd

\section{Trophin changes associated with NPC transplantation}

To date, a few studies have explored trophin production in tissue transplanted with neural cells [21,47,94]. Lu et al. reported expression of NGF, BDNF, and GDNF in tissue transplanted with C17.2 NPCs using immunohistochemistry and RT-PCR [47]. Yan et al. characterized the same 3 trophins and found similar results [94]. C17.2 are progenitor cells of the neonatal mouse cerebellum immortalized by transduction with the avian myc oncogene so, it is uncertain whether results from these cells will be similar to NPCs from other sources. In a different transplant paradigm, Sharp et al. found that OPCs produce TGF- $\beta 1$ and neuregulins 1 and 2 in vitro and that hepatocyte growth factor was significantly upregulated in the region of the injury epicentre after OPC transplantation, while TGF- $\beta 2$ was not significantly changed [21]. However, this study did not report expression data for any of the trophins investigated in the present study [21].

In the present study, Paradigm 1 found that NPC transplantation was associated with a significant reduction in 


\section{Expression of Inflammatory Mediators in Cell Transplantation Strategies} For Spinal Cord Injury Repair

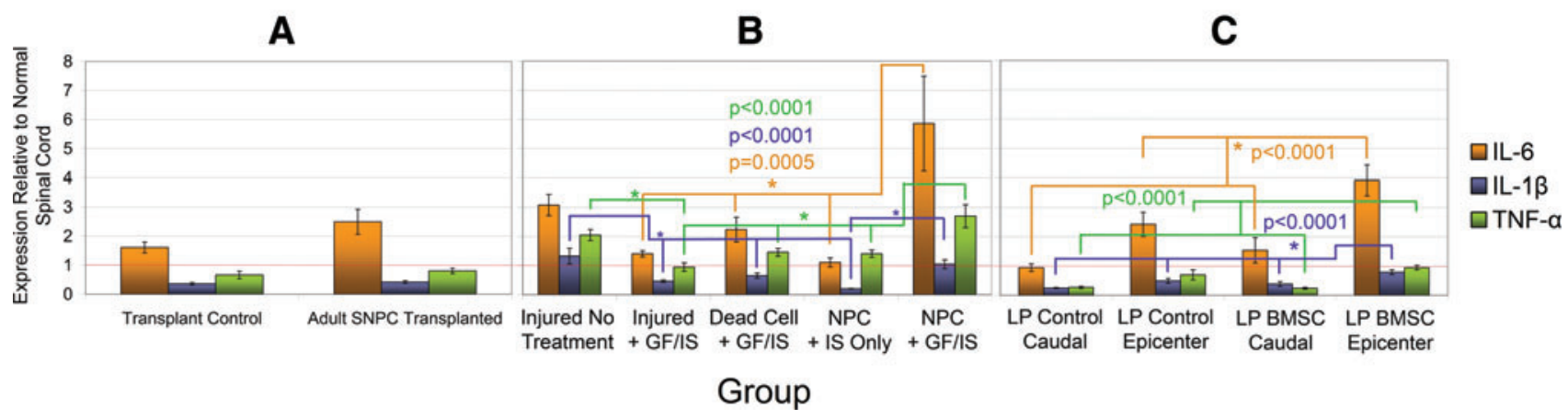

FIG. 6. Cellular transplantation upregulates inflammatory mediators. Expression of inflammatory mediators $I L-6$, $I L-1 \beta$, and TNF- $\alpha$ is plotted for Paradigms 1, 2, and 3 in $\mathbf{A}, \mathbf{B}$, and $\mathbf{C}$ respectively. The same samples investigated in trophin studies have been employed in this analysis. In all 3 transplantation paradigms, the presence of transplanted cells led to the upregulation of the inflammatory mediators. For A and C, qPCR was performed in triplicate; for B, it was performed in quadruplicate. For C, LP reflects administration of BMSCs via lumbar puncture; caudal refers to a control region of uninjured tissue caudal to the epicenter.

Sample sizes: Paradigm 1: NPC Transplanted $n=4$, Control $n=3$ Paradigm 2: Injured No Treatment $n=3$, Injured + GF/IS $n=3$, Dead Cell + GF/IS $n=4$, NPC + IS Only $n=3, N P C+$ GF/IS $n=3$ Paradigm 3: LP Control Caudal $n=3$, LP Control Epicenter $n=3$, BMSC Control Caudal $n=3$, BMSC Control Epicenter $n=3$ *denotes $P<0.05$. IL-6, interleukin 6; IL-1 $\beta$, interleukin 1 beta; TNF- $\alpha$, tumour necrosis factor alpha. Color images available online at www.liebertonline.com/scd

$B D N F$ and GGF2 expression in nonenriched perilesional tissue, while IGF-1 and CNTF expression were significantly increased. In Paradigm 2, NPC transplantation and pharmacotherapy alone was associated with significant perilesional downregulation of IGF-1 and TGF- $\beta 1$ in nonenriched tissue. The difference in these results may stem from a different time post-injury or the differential presence of minocycline or cyclosporin. Since the magnitude of these differences in both paradigms are small, it is also possible that these differences reflect biological variability without biological significance.

\section{Synergistic changes in trophin expression associated with co-administration of NPCs pharmacotherapy and trophin infusion}

In Paradigm 2, numerous control groups allow a delineation of how different aspects of the applied combinatorial treatment strategy altered trophin expression. The effect of minocycline, cyclosporin, or trophin infusion on endogenous trophin production has not been previously reported to our knowledge. We have shown that animals treated with the anti-inflammatory and neuroprotective drugs minocycline and cyclosporin and intrathecal infusion of EGF, bFGF, and PDGF- $A$ by implanted osmotic mini-pump after sham transplantation demonstrate modest but significant downregulation of EGF, bFGF, IGF-1, TGF- $\beta 1$, and VEGF- $A$ in perilesional spinal cord tissue. Downregulation of $E G F$ and $b F G F$ may represent negative feedback in the context of exogenous administration.

Transplantation of NPCs and pharmacotherapy alone was associated with significant downregulation of IGF-1 and TGF- $\beta 1$ in perilesional tissue. The addition of a trophin infusion led to marked and statistically significant upregulation of the neurotrophins, GDNF, LIF and bFGF, demonstrating a synergistic effect of these combinatorial treatments. These expression changes could assist recovery from SCI.
$B D N F$ has been demonstrated to improve survival [95-101] and regrowth $[98,99]$ of motor neurons and to prevent apoptosis of oligodendrocytes [15]. NT-4/5 has similar effects to $B D N F$ likely because both bind to the Trk $B$ receptor $[74,101,102]$. NT-3 has similar effects $[103,104]$ and may also enhance angiogenesis [105] and inhibit myelination $[106,107]$. GDNF has been demonstrated to promote the survival and outgrowth of many types of neurons [108,109]. $b F G F$ is known to stimulate angiogenesis and the proliferation of NPCs in the adult spinal cord [13]. bFGF has also demonstrated neuroprotective effects on neurons [110] and oligodendrocytes [111] but was also shown to increase scar formation around CNS lesions [55]. The putative effects of NGF and LIF have been described above.

In this transplant paradigm, the presence of transplanted cells alone was associated with a significant increase in EGF and bFGF (when considering both the NPC + GF/IS and $N P C+I S$ Only groups). However, trophin infusion was not associated with a statistically significant increase in these factors. EGF is a mitogen for many cell types that has also been shown to stimulate survival and outgrowth of neurons [112].

We hypothesized that the expression changes reported in transplanted cord homogenates predominantly reflect expression in host cells as exogenous cells were demonstrated to be a minority of the cells in this tissue. To explore this possibility and to characterize trophin expression in a pure sample of NPCs isolated from tissue one week after transplantation, we analyzed eYFP positive and negative specimens obtained by FACS sorting perilesional transplanted tissue from 3 NPC + GF/IS animals. Despite pooling cells obtained from 3 samples, trophin expression was near the limit of detection mandating careful interpretation. Careful interpretation is also warranted, because tissue harvest, dissociation, and FACS sorting may have influenced trophin expression; moreover, FACS may have introduced a selection bias for healthier cells-potentially those expressing 
higher than average trophin levels. These results suggest, however, that trophin changes in both host and transplanted cells may contribute to the trophin upregulation seen in the transplanted cord homogenate. Elevated trophin levels from both sources, thus, appear poised to contribute to neural repair processes.

\section{Trophin changes associated with BMSC transplantation}

Since neural differentiation of BMSCs has been unconvincing to date $[4,113]$, trophin augmentation has seemed a likely mechanism of action for BMSCs especially when transplanted cells fail to survive [10]. Potential mechanisms by which BMSCs may function have been thoroughly reviewed by Parr et al. [10]. Consistent with a possible trophic effect, multiple groups have noted cell and tissue sparing or enhanced axonal regeneration after BMSC transplantation [23,24,114-118]. Numerous groups have also noted reduced cyst formation after BMSC transplantation [8,9,119-121]. Although BMSCs have been reported to produce NGF, $B D N F$, and $V E G F$ in vitro $[16,122,123]$, we are unaware of previous studies exploring trophin production by these cells after transplantation or by the host in response to their transplantation.

The present study demonstrates that intrathecal transplantation of BMSCs via lumbar puncture is associated with changes in trophin expression one week post-transplant (2 week postinjury) (Fig. 5). Here, BMSC transplantation significantly increased expression of NGF, LIF, IGF-1, and $T G F-\beta 1$ relative to injured control tissue in distinct animals and significantly reduced expression of PDGF-A. Although the BMSC marker eGFP was also detected in caudal control tissue remote from the injury, which is consistent with the distribution of cells after intrathecal transplantation [35], there was no significant change in trophin expression in this uninjured tissue. This pattern of trophin upregulation is distinct from that seen resulting from NPC transplantation in either Paradigms 1 or 2 . Interestingly, this is the same pattern of trophin alteration we twice demonstrated after SCI (Fig. 1). This raises the possibility that BMSCs, at least when transplanted via intrathecal infusion, may benefit by further upregulating trophins already upregulated by the SCI itself. A possible explanation for this effect would be an exacerbation of the inflammatory response known to follow SCI, prompting our analysis of inflammatory mediators in all 3 transplant paradigms.

\section{Expression of inflammatory mediators following cellular transplantation}

The inflammatory response that follows SCI has been thoroughly characterized [124]. IL-1, IL-6, and TNF- $\alpha$ are 3 commonly characterized inflammatory mediators known to be upregulated after SCI $[49,125,126]$. As shown in Fig. 6, increased expression of inflammatory mediators was demonstrated in injured spinal cord tissue relative to the uninjured cord. In Paradigms 1 and 3 (Fig. 6A, C) cellular transplantation increased the expression of inflammatory mediators relative to control tissue when both groups of animals were treated with cyclosporin. This did not reach statistical significance except for $I L-1 \beta$ in Paradigm 3. In
Paradigm 2, immunosuppression with minocycline and cycosporin appeared to be effective as the expression of inflammatory mediators was lower in animals receiving these immunosuppressants than injured, untreated animals that did not receive these drugs. The exception, however, was the group treated with NPC transplantation and implantation of a trophin pump (NPC + GF/IS). Paralleling the synergistic increase in trophins in this group, a synergistic increase in inflammatory mediator expression was also seen. It is possible that this could be a physical or chemical effect of trophin infusion [127-129]. Given the inter-relationship of NGF and the inflammatory cascade $[67,71]$, it is possible that the increase in trophin response and the increase in inflammatory mediators is inter-related. Indeed, activated microglia and macrophages have been reported to produce NGF, NT-3, and $b F G F[130]$. It is also probable that the robust upregulation of NGF noted in the group transplanted with freezethaw killed NPCs stems from an immune response to this transplanted organic matter (Fig. 3B).

It is interesting to note that BMSCs have been reported by several groups to have anti-inflammatory properties [113] after transplantation. In the context of our findings, it is possible that the upregulation of the anti-inflammatory factor TGF- $\beta 1$ is dominant over the upregulated proinflammatory cytokines $I L-1 \beta, I L-6$ and TNF- $\alpha$.

In conclusion, the present study significantly increases our understanding of trophic factor production in the normal and injured spinal cord. We have also thoroughly characterized trophin production in 3 preclinical cellular transplantation paradigms aimed at ameliorating the deficits of SCI. Although the biological activities of measured trophins is uncertain given the distinct effects of their pro-forms and binding to high- or low-affinity receptors, our work suggests that trophins could contribute to the benefits seen in all 3 transplantation paradigms. Future work will be required to determine whether this trophin elevation is responsible for the functional improvements seen, and if so, which trophins-alone or in combination-are responsible.

\section{Acknowledgments}

The authors wish to thank Drs. Xing-Hua Wang and Armand Keating for provision of BMSCs. The authors also wish to thank the Craig H. Neilsen Foundation, the Cervical Spine Research Society, and the Canadian Institutes of Health Research who provided funding for these experiments. G. Hawryluk was supported by fellowships from Johnson and Johnson Medical Products, the McLaughlin Center for Molecular Medicine, and the Congress of Neurological Surgeons/American Association of Neurological Surgeons.

\section{Author Disclosure Statement}

No competing financial interests exist.

\section{References}

1. Hawryluk GW and MG Fehlings. (2009). Cellular transplantation approaches for repair of the injured spinal cord: ongoing and pending clinical trials. Top SCI Rehabil 14: 47-61.

2. Pearse DD, FC Pereira, AE Marcillo, ML Bates, YA Berrocal, MT Filbin and MB Bunge. (2004). cAMP and 
Schwann cells promote axonal growth and functional recovery after spinal cord injury. Nat Med 10:610-616.

3. Erceg S, M Ronaghi, M Oria, MG Rosello, MA Arago, MG Lopez, I Radojevic, V Moreno-Manzano, FJ RodriguezJimenez, et al. (2010). Transplanted oligodendrocytes and motoneuron progenitors generated from human embryonic stem cells promote locomotor recovery after spinal cord transection. Stem Cells 28:1541-1549.

4. Tetzlaff W, EB Okon, S Karimi-Abdolrezaee, CE Hill, JS Sparling, JR Plemel, WT Plunet, EC Tsai, D Baptiste, et al. (2011). A systematic review of cellular transplantation therapies for spinal cord injury. J Neurotrauma 28:1611-1682.

5. Enzmann GU, RL Benton, JF Talbott, Q Cao and SR Whittemore. (2006). Functional considerations of stem cell transplantation therapy for spinal cord repair. J Neurotrauma 23:479-495.

6. Hawryluk GW and MG Fehlings. (2008). The center of the spinal cord may be central to its repair. Cell Stem Cell 3:230-232.

7. Koshizuka S, S Okada, A Okawa, M Koda, M Murasawa, M Hashimoto, T Kamada, K Yoshinaga, M Murakami, H Moriya and M Yamazaki. (2004). Transplanted hematopoietic stem cells from bone marrow differentiate into neural lineage cells and promote functional recovery after spinal cord injury in mice. J Neuropathol Exp Neurol 63:64-72.

8. Ohta M, Y Suzuki, T Noda, Y Ejiri, M Dezawa, K Kataoka, H Chou, N Ishikawa, N Matsumoto, et al. (2004). Bone marrow stromal cells infused into the cerebrospinal fluid promote functional recovery of the injured rat spinal cord with reduced cavity formation. Exp Neurol 187:266-278.

9. Wu S, Y Suzuki, Y Ejiri, T Noda, H Bai, M Kitada, K Kataoka, M Ohta, H Chou and C Ide. (2003). Bone marrow stromal cells enhance differentiation of cocultured neurosphere cells and promote regeneration of injured spinal cord. J Neurosci Res 72:343-351.

10. Parr AM, CH Tator and A Keating. (2007). Bone marrowderived mesenchymal stromal cells for the repair of central nervous system injury. Bone Marrow Transplant 40: 609-619.

11. Chen J, Y Li, M Katakowski, X Chen, L Wang, D Lu, M Lu, SC Gautam and M Chopp. (2003). Intravenous bone marrow stromal cell therapy reduces apoptosis and promotes endogenous cell proliferation after stroke in female rat. J Neurosci Res 73:778-786.

12. Widenfalk J, K Lundströmer, M Jubran, S Brene and L Olson. (2001). Neurotrophic factors and receptors in the immature and adult spinal cord after mechanical injury or kainic acid. J Neurosci 21:3457-3475.

13. Mocchetti I and JR Wrathall. (1995). Neurotrophic factors in central nervous system trauma. J Neurotrauma 12:853-870.

14. Namiki J, A Kojima and CH Tator. (2000). Effect of brainderived neurotrophic factor, nerve growth factor, and neurotrophin-3 on functional recovery and regeneration after spinal cord injury in adult rats. J Neurotrauma 17:1219-1231.

15. Koda M, M Murakami, H Ino, K Yoshinaga, O Ikeda, M Hashimoto, M Yamazaki, C Nakayama and H Moriya. (2002). Brain-derived neurotrophic factor suppresses delayed apoptosis of oligodendrocytes after spinal cord injury in rats. J Neurotrauma 19:777-785.

16. Neuhuber B, B Timothy Himes, JS Shumsky, G Gallo and I Fischer. (2005). Axon growth and recovery of function supported by human bone marrow stromal cells in the injured spinal cord exhibit donor variations. Brain Res 1035:73-85.

17. Tolwani RJ, JM Cosgaya, S Varma, R Jacob, LE Kuo and EM Shooter. (2004). BDNF overexpression produces a longterm increase in myelin formation in the peripheral nervous system. J Neurosci Res 77:662-669.

18. Hempstead BL and JL Salzer. (2002). A glial spin on neurotrophins. Science 298:1184-1186.

19. Nakamura M, H Okano, Y Toyama, HN Dai, TP Finn and BS Bregman. (2005). Transplantation of embryonic spinal cord-derived neurospheres support growth of supraspinal projections and functional recovery after spinal cord injury in the neonatal rat. J Neurosci Res 81:457-468.

20. Chen Q, L Zhou and HD Shine. (2006). Expression of neurotrophin-3 promotes axonal plasticity in the acute but not chronic injured spinal cord. J Neurotrauma 23:12541260.

21. Sharp J, J Frame, M Siegenthaler, G Nistor and HS Keirstead. (2010). Human embryonic stem cell-derived oligodendrocyte progenitor cell transplants improve recovery after cervical spinal cord injury. Stem Cells 28: 152-163.

22. Bambakidis NC and RH Miller. (2004). Transplantation of oligodendrocyte precursors and sonic hedgehog results in improved function and white matter sparing in the spinal cords of adult rats after contusion. Spine J 4:16-26.

23. Ankeny DP, DM McTigue and LB Jakeman. (2004). Bone marrow transplants provide tissue protection and directional guidance for axons after contusive spinal cord injury in rats. Exp Neurol 190:17-31.

24. Chopp M, XH Zhang, Y Li, L Wang, J Chen, D Lu, M Lu and M Rosenblum. (2000). Spinal cord injury in rat: treatment with bone marrow stromal cell transplantation. Neuroreport 11:3001-3005.

25. Hawryluk GWJ, A Mothe, M Chamankhah, J Wang, C Tator and MG Fehlings. (2011). In vitro characterization of trophic factor expression in neural precursor cells. [Epub ahead of print]; DOI: 10.1089/scd.2011.0242.

26. Strauss S. (2010). Geron trial resumes, but standards for stem cell trials remain elusive. Nat Biotechnol 28:989-990.

27. Sykova E, A Homola, R Mazanec, H Lachmann, SL Konradova, P Kobylka, R Padr, J Neuwirth, V Komrska, et al. (2006). Autologous bone marrow transplantation in patients with subacute and chronic spinal cord injury. Cell Transplant 15:675-687.

28. Yoon SH, YS Shim, YH Park, JK Chung, JH Nam, MO Kim, HC Park, SR Park, BH Min, EY Kim, BH Choi, H Park and Y Ha. (2007). Complete spinal cord injury treatment using autologous bone marrow cell transplantation and bone marrow stimulation with granulocyte macrophage-colony stimulating factor: phase I/II clinical trial. Stem Cells 25:2066-2073.

29. Hakamata Y, K Tahara, H Uchida, Y Sakuma, M Nakamura, A Kume, T Murakami, M Takahashi, R Takahashi, et al. (2001). Green fluorescent protein-transgenic rat: a tool for organ transplantation research. Biochem Biophys Res Commun 286:779-785.

30. Mothe AJ and CH Tator. (2008). Transplanted neural stem/ progenitor cells generate myelinating oligodendrocytes and Schwann cells in spinal cord demyelination and dysmyelination. Exp Neurol 213:176-190.

31. Karimi-Abdolrezaee S, E Eftekharpour, J Wang, CM Morshead and MG Fehlings. (2006). Delayed transplantation of adult neural precursor cells promotes remyelination 
and functional neurological recovery after spinal cord injury. J Neurosci 26:3377-3389.

32. Parr AM, I Kulbatski, T Zahir, X Wang, C Yue, A Keating and CH Tator. (2008). Transplanted adult spinal cordderived neural stem/progenitor cells promote early functional recovery after rat spinal cord injury. Neuroscience 155:760-770.

33. Clark BR, C Jamieson and A Keating. (1997). Human longterm bone marrow culture. Methods Mol Biol 75:249-256.

34. Dominici M, K Le Blanc, I Mueller, I Slaper-Cortenbach, F Marini, D Krause, R Deans, A Keating, D Prockop and E Horwitz. (2006). Minimal criteria for defining multipotent mesenchymal stromal cells. The International Society for Cellular Therapy position statement. Cytotherapy 8:315-317.

35. Mothe AJ, G Bozkurt, J Catapano, J Zabojova, X Wang, A Keating and $\mathrm{CH}$ Tator. (2011). Intrathecal transplantation of stem cells by lumbar puncture for thoracic spinal cord injury in the rat. Spinal Cord 49:967-973.

36. Rivlin AS and CH Tator. (1978). Effect of duration of acute spinal cord compression in a new acute cord injury model in the rat. Surg Neurol 10:38-43.

37. Modo M, RP Stroemer, E Tang, S Patel and H Hodges. (2003). Effects of implantation site of dead stem cells in rats with stroke damage. Neuroreport 14:39-42.

38. Wilkins A, S Chandran and A Compston. (2001). A role for oligodendrocyte-derived IGF-1 in trophic support of cortical neurons. Glia 36:48-57.

39. Giehl KM, A Schutte, P Mestres and Q Yan. (1998). The survival-promoting effect of glial cell line-derived neurotrophic factor on axotomized corticospinal neurons in vivo is mediated by an endogenous brain-derived neurotrophic factor mechanism. J Neurosci 18:7351-7360.

40. Deleyrolle L, S Marchal-Victorion, C Dromard, V Fritz, M Saunier, JC Sabourin, C Tran Van Ba, A Privat and JP Hugnot. (2006). Exogenous and fibroblast growth factor 2/ epidermal growth factor-regulated endogenous cytokines regulate neural precursor cell growth and differentiation. Stem Cells 24:748-762.

41. Magy L, C Mertens, V Avellana-Adalid, M Keita, F Lachapelle, B Nait-Oumesmar, B Fontaine and A BaronVan Evercooren. (2003). Inducible expression of FGF2 by a rat oligodendrocyte precursor cell line promotes CNS myelination in vitro. Exp Neurol 184:912-922.

42. Du Y and CF Dreyfus. (2002). Oligodendrocytes as providers of growth factors. J Neurosci Res 68:647-654.

43. Albrecht PJ, JC Murtie, JK Ness, JM Redwine, JR Enterline, RC Armstrong and SW Levison. (2003). Astrocytes produce CNTF during the remyelination phase of viral-induced spinal cord demyelination to stimulate FGF-2 production. Neurobiol Dis 13:89-101.

44. Blesch A, HS Uy, RJ Grill, JG Cheng, PH Patterson and MH Tuszynski. (1999). Leukemia inhibitory factor augments neurotrophin expression and corticospinal axon growth after adult CNS injury. J Neurosci 19:3556-3566.

45. Zai LJ, S Yoo and JR Wrathall. (2005). Increased growth factor expression and cell proliferation after contusive spinal cord injury. Brain Res 1052:147-155.

46. Fressinaud C. (2005). Repeated injuries dramatically affect cells of the oligodendrocyte lineage: effects of PDGF and NT-3 in vitro. Glia 49:555-566.

47. Lu P, LL Jones, EY Snyder and MH Tuszynski. (2003). Neural stem cells constitutively secrete neurotrophic factors and promote extensive host axonal growth after spinal cord injury. Exp Neurol 181:115-129.
48. Nakamura M and BS Bregman. (2001). Differences in neurotrophic factor gene expression profiles between neonate and adult rat spinal cord after injury. Exp Neurol 169:407415.

49. Nakamura M, RA Houghtling, L MacArthur, BM Bayer and BS Bregman. (2003). Differences in cytokine gene expression profile between acute and secondary injury in adult rat spinal cord. Exp Neurol 184:313-325.

50. Okragly AJ and M Haak-Frendscho. (1997). An acidtreatment method for the enhanced detection of GDNF in biological samples. Exp Neurol 145:592-596.

51. Dougherty KD, CF Dreyfus and IB Black. (2000). Brainderived neurotrophic factor in astrocytes, oligodendrocytes, and microglia/macrophages after spinal cord injury. Neurobiol Dis 7:574-585.

52. Follesa P, JR Wrathall and I Mocchetti. (1994). Induction of bFGF mRNA in spinal cord trauma. Mol Brain Res 22:1-8.

53. Dreyfus CF, X Dai, LD Lercher, BR Racey, WJ Friedman and IB Black. (1999). Expression of neurotrophins in the adult spinal cord in vivo. J Neurosci Res 56:1-7.

54. Nieto-Sampedro M, ER Lewis, CW Cotman, M Manthorpe, SD Skaper, G Barbin, FM Longo and S Varon. (1982). Brain injury causes a time-dependent increase in neuronotrophic activity at the lesion site. Science 217:860-861.

55. Finklestein SP, PJ Apostolides, CG Caday, J Prosser, MF Philips and M Klagsbrun. (1988). Increased basic fibroblast growth factor (bFGF) immunoreactivity at the site of focal brain wounds. Brain Res 460:253-259.

56. Zvarova K, E Murray and MA Vizzard. (2004). Changes in galanin immunoreactivity in rat lumbosacral spinal cord and dorsal root ganglia after spinal cord injury. J Comp Neurol 475:590-603.

57. Tokumine J, O Kakinohana, D Cizkova, DW Smith and M Marsala. (2003). Changes in spinal GDNF, BDNF, and NT-3 expression after transient spinal cord ischemia in the rat. J Neurosci Res 74:552-561.

58. Uchida K, H Baba, Y Maezawa, S Furukawa, M Omiya, Y Kokubo, C Kubota and H Nakajima. (2003). Increased expression of neurotrophins and their receptors in the mechanically compressed spinal cord of the spinal hyperostotic mouse (twy/twy). Acta Neuropathol 106:29-36.

59. Ikeda O, M Murakami, H Ino, M Yamazaki, T Nemoto, M Koda, C Nakayama and H Moriya. (2001). Acute upregulation of brain-derived neurotrophic factor expression resulting from experimentally induced injury in the rat spinal cord. Acta Neuropathol 102:239-245.

60. Li XL, W Zhang, X Zhou, XY Wang, HT Zhang, DX Qin, H Zhang, Q Li, M Li and TH Wang. (2007). Temporal changes in the expression of some neurotrophins in spinal cord transected adult rats. Neuropeptides 41:135-143.

61. Zhang HT, ZY Gao, YZ Chen and TH Wang. (2008). Temporal changes in the level of neurotrophins in the spinal cord and associated precentral gyrus following spinal hemisection in adult Rhesus monkeys. J Chem Neuroanat 36:138-143.

62. Johnson RA, AJ Okragly, M Haak-Frendscho and GS Mitchell. (2000). Cervical dorsal rhizotomy increases brainderived neurotrophic factor and neurotrophin-3 expression in the ventral spinal cord. J Neurosci 20:RC77.

63. Brown A, MJ Ricci and LC Weaver. (2004). NGF message and protein distribution in the injured rat spinal cord. Exp Neurol 188:115-127.

64. Gulino R, SA Lombardo, A Casabona, G Leanza and V Perciavalle. (2004). Levels of brain-derived neurotrophic 
factor and neurotrophin- 4 in lumbar motoneurons after low-thoracic spinal cord hemisection. Brain Res 1013:174181.

65. Qin DX, XL Zou, W Luo, W Zhang, HT Zhang, XL Li, H Zhang, XY Wang and TH Wang. (2006). Expression of some neurotrophins in the spinal motoneurons after cord hemisection in adult rats. Neurosci Lett 410: 222-227.

66. Hajebrahimi Z, SJ Mowla, M Movahedin and M Tavallaei. (2008). Gene expression alterations of neurotrophins, their receptors and prohormone convertases in a rat model of spinal cord contusion. Neurosci Lett 441:261-266.

67. Hayashi M, T Ueyama, K Nemoto, T Tamaki and E Senba. (2000). Sequential mRNA expression for immediate early genes, cytokines, and neurotrophins in spinal cord injury. J Neurotrauma 17:203-218.

68. Kerr BJ and PH Patterson. (2004). Potent pro-inflammatory actions of leukemia inhibitory factor in the spinal cord of the adult mouse. Exp Neurol 188:391-407.

69. Bandtlow CE, M Meyer, D Lindholm, M Spranger, $\mathrm{R}$ Heumann and H Thoenen. (1990). Regional and cellular codistribution of interleukin 1 beta and nerve growth factor mRNA in the adult rat brain: possible relationship to the regulation of nerve growth factor synthesis. J Cell Biol 111:1701-1711.

70. Saporito MS, HM Wilcox, KC Hartpence, ME Lewis, JL Vaught and S Carswell. (1993). Pharmacological induction of nerve growth factor mRNA in adult rat brain. Exp Neurol 123:295-302.

71. Spranger M, D Lindholm, C Bandtlow, R Heumann, H Gnahn, M Naher-Noe and H Thoenen. (1990). Regulation of nerve growth factor (NGF) synthesis in the rat central nervous system: comparison between the effects of interleukin-1 and various growth factors in astrocyte cultures and in vivo. Eur J Neurosci 2:69-76.

72. Beattie MS, AW Harrington, R Lee, JY Kim, SL Boyce, FM Longo, JC Bresnahan, BL Hempstead and SO Yoon. (2002). ProNGF induces p75-mediated death of oligodendrocytes following spinal cord injury. Neuron 36:375-386.

73. Kurek JB, TM Bennett, JJ Bower, CM Muldoon and L Austin. (1998). Leukaemia inhibitory factor (LIF) production in a mouse model of spinal trauma. Neurosci Lett 249:1-4.

74. Sendtner M, R Gotz, B Holtmann, JL Escary, Y Masu, P Carroll, E Wolf, G Brem, P Brulet and H Thoenen. (1996). Cryptic physiological trophic support of motoneurons by LIF revealed by double gene targeting of CNTF and LIF. Curr Biol 6:686-694.

75. Hughes RA, M Sendtner and H Thoenen. (1993). Members of several gene families influence survival of rat motoneurons in vitro and in vivo. J Neurosci Res 36: 663-671.

76. Vartanian T, Y Li, M Zhao and K Stefansson. (1995). Interferon-gamma-induced oligodendrocyte cell death: implications for the pathogenesis of multiple sclerosis. Mol Med 1:732-743.

77. Azari MF, C Profyris, T Karnezis, CC Bernard, DH Small, SS Cheema, E Ozturk, I Hatzinisiriou and S Petratos. (2006). Leukemia inhibitory factor arrests oligodendrocyte death and demyelination in spinal cord injury. J Neuropathol Exp Neurol 65:914-929.

78. Kerr BJ and PH Patterson. (2005). Leukemia inhibitory factor promotes oligodendrocyte survival after spinal cord injury. Glia 51:73-79.
79. Bugga L, RA Gadient, K Kwan, CL Stewart and PH Patterson. (1998). Analysis of neuronal and glial phenotypes in brains of mice deficient in leukemia inhibitory factor. J Neurobiol 36:509-524.

80. Kahn MA and J De Vellis. (1994). Regulation of an oligodendrocyte progenitor cell line by the interleukin- 6 family of cytokines. Glia 12:87-98.

81. Mayer M, K Bhakoo and M Noble. (1994). Ciliary neurotrophic factor and leukemia inhibitory factor promote the generation, maturation and survival of oligodendrocytes in vitro. Development 120:143-153.

82. Richards LJ, TJ Kilpatrick, R Dutton, SS Tan, DP Gearing, PF Bartlett and M Murphy. (1996). Leukaemia inhibitory factor or related factors promote the differentiation of neuronal and astrocytic precursors within the developing murine spinal cord. Eur J Neurosci 8:291-299.

83. Hollis ER, 2nd, P Lu, A Blesch and MH Tuszynski. (2009). IGF-I gene delivery promotes corticospinal neuronal survival but not regeneration after adult CNS injury. Exp Neurol 215:53-59.

84. Nakao Y, H Otani, T Yamamura, R Hattori, M Osako and H Imamura. (2001). Insulin-like growth factor 1 prevents neuronal cell death and paraplegia in the rabbit model of spinal cord ischemia. J Thorac Cardiovasc Surg 122:136-143.

85. Ozdinler PH and JD Macklis. (2006). IGF-I specifically enhances axon outgrowth of corticospinal motor neurons. Nat Neurosci 9:1371-1381.

86. Hamada Y, T Ikata, S Katoh, K Katoh, M Niwa, Y Tsutsumishita and K Fukuzawa. (1996). Effects of exogenous transforming growth factor-beta 1 on spinal cord injury in rats. Neurosci Lett 203:97-100.

87. Prehn JH, C Backhauss and J Krieglstein. (1993). Transforming growth factor-beta 1 prevents glutamate neurotoxicity in rat neocortical cultures and protects mouse neocortex from ischemic injury in vivo. J Cereb Blood Flow Metab 13:521-525.

88. Krady JK, HW Lin, CM Liberto, A Basu, SG Kremlev and SW Levison. (2008). Ciliary neurotrophic factor and interleukin-6 differentially activate microglia. J Neurosci Res 86:1538-1547.

89. Liu Y, S Figley, SK Spratt, G Lee, D Ando, R Surosky and MG Fehlings. (2010). An engineered transcription factor which activates VEGF-A enhances recovery after spinal cord injury. Neurobiol Dis 37:384-393.

90. Rossi SL, G Nistor, T Wyatt, HZ Yin, AJ Poole, JH Weiss, MJ Gardener, S Dijkstra, DF Fischer and HS Keirstead. (2010). Histological and functional benefit following transplantation of motor neuron progenitors to the injured rat spinal cord. PLoS One 5:e11852.

91. Rossi SL and HS Keirstead. (2009). Stem cells and spinal cord regeneration. Curr Opin Biotechnol 20:552-562.

92. Sykova E, P Jendelova, L Urdzikova, P Lesny and A Hejcl. (2006). Bone marrow stem cells and polymer hydrogelstwo strategies for spinal cord injury repair. Cell Mol Neurobiol 26:1113-1129.

93. Pearse DD and MB Bunge. (2006). Designing cell- and genebased regeneration strategies to repair the injured spinal cord. J Neurotrauma 23:438-452.

94. Yan J, AM Welsh, SH Bora, EY Snyder and VE Koliatsos. (2004). Differentiation and tropic/trophic effects of exogenous neural precursors in the adult spinal cord. J Comp Neurol 480:101-114.

95. Clatterbuck RE, DL Price and VE Koliatsos. (1994). Further characterization of the effects of brain-derived neurotrophic 
factor and ciliary neurotrophic factor on axotomized neonatal and adult mammalian motor neurons. J Comp Neurol 342:45-56.

96. Dittrich F, G Ochs, A Grosse-Wilde, U Berweiler, Q Yan, JA Miller, KV Toyka and M Sendtner. (1996). Pharmacokinetics of intrathecally applied BDNF and effects on spinal motoneurons. Exp Neurol 141:225-239.

97. Friedman B, D Kleinfeld, NY Ip, VM Verge, R Moulton, $\mathrm{P}$ Boland, E Zlotchenko, RM Lindsay and L Liu. (1995). BDNF and NT-4/ 5 exert neurotrophic influences on injured adult spinal motor neurons. J Neurosci 15:1044-1056.

98. Kishino A, Y Ishige, T Tatsuno, C Nakayama and H Noguchi. (1997). BDNF prevents and reverses adult rat motor neuron degeneration and induces axonal outgrowth. Exp Neurol 144:273-286.

99. Novikov L, L Novikova and JO Kellerth. (1995). Brainderived neurotrophic factor promotes survival and blocks nitric oxide synthase expression in adult rat spinal motoneurons after ventral root avulsion. Neurosci Lett 200:45-48.

100. Nakahara Y, FH Gage and MH Tuszynski. (1996). Grafts of fibroblasts genetically modified to secrete NGF, BDNF, NT3, or basic FGF elicit differential responses in the adult spinal cord. Cell Transplant 5:191-204.

101. Yan Q, J Elliott and WD Snider. (1992). Brain-derived neurotrophic factor rescues spinal motor neurons from axotomy-induced cell death. Nature 360:753-755.

102. Kobayashi NR, DP Fan, KM Giehl, AM Bedard, SJ Wiegand and W Tetzlaff. (1997). BDNF and NT-4/5 prevent atrophy of rat rubrospinal neurons after cervical axotomy, stimulate GAP-43 and Talpha1-tubulin mRNA expression, and promote axonal regeneration. J Neurosci 17:9583-9595.

103. Grill R, K Murai, A Blesch, FH Gage and MH Tuszynski. (1997). Cellular delivery of neurotrophin-3 promotes corticospinal axonal growth and partial functional recovery after spinal cord injury. J Neurosci 17:5560-5572.

104. Giehl KM and W Tetzlaff. (1996). BDNF and NT-3, but not NGF, prevent axotomy-induced death of rat corticospinal neurons in vivo. Eur J Neurosci 8:1167-1175.

105. Kraemer R and BL Hempstead. (2003). Neurotrophins: novel mediators of angiogenesis. Front Biosci 8:s1181s1186.

106. Yamauchi J, JR Chan and EM Shooter. (2004). Neurotrophins regulate Schwann cell migration by activating divergent signaling pathways dependent on Rho GTPases. Proc Natl Acad Sci U S A 101:8774-8779.

107. Chan JR, JM Cosgaya, YJ Wu and EM Shooter. (2001). Neurotrophins are key mediators of the myelination program in the peripheral nervous system. Proc Natl Acad Sci U S A 98:14661-14668.

108. Lin LF, DH Doherty, JD Lile, S Bektesh and F Collins. (1993). GDNF: a glial cell line-derived neurotrophic factor for midbrain dopaminergic neurons. Science 260:11301132.

109. Ramer MS, JV Priestley and SB McMahon. (2000). Functional regeneration of sensory axons into the adult spinal cord. Nature 403:312-316.

110. Teng YD, I Mocchetti and JR Wrathall. (1998). Basic and acidic fibroblast growth factors protect spinal motor neurones in vivo after experimental spinal cord injury. Eur J Neurosci 10:798-802.

111. Yasuda T, J Grinspan, J Stern, B Franceschini, P Bannerman and D Pleasure. (1995). Apoptosis occurs in the oligodendroglial lineage, and is prevented by basic fibroblast growth factor. J Neurosci Res 40:306-317.
112. Yamada M, T Ikeuchi and H Hatanaka. (1997). The neurotrophic action and signalling of epidermal growth factor. Prog Neurobiol 51:19-37.

113. Wright KT, W El Masri, A Osman, J Chowdhury and WE Johnson. (2010). Bone marrow for the treatment of spinal cord injury: mechanisms and clinical application. Stem Cells 29:169-178.

114. Kamada T, M Koda, M Dezawa, K Yoshinaga, M Hashimoto, S Koshizuka, Y Nishio, $\mathrm{H}$ Moriya and $\mathrm{M}$ Yamazaki. (2005). Transplantation of bone marrow stromal cell-derived Schwann cells promotes axonal regeneration and functional recovery after complete transection of adult rat spinal cord. J Neuropathol Exp Neurol 64: 37-45.

115. Lu P, LL Jones and MH Tuszynski. (2005). BDNFexpressing marrow stromal cells support extensive axonal growth at sites of spinal cord injury. Exp Neurol 191: 344-360.

116. Nandoe Tewarie RD, A Hurtado, GJ Ritfeld, ST Rahiem, DF Wendell, MM Barroso, JA Grotenhuis and M Oudega. (2009). Bone marrow stromal cells elicit tissue sparing after acute but not delayed transplantation into the contused adult rat thoracic spinal cord. J Neurotrauma 26: 2313-2322.

117. Someya Y, M Koda, M Dezawa, T Kadota, M Hashimoto, $\mathrm{T}$ Kamada, Y Nishio, R Kadota, C Mannoji, et al. (2008). Reduction of cystic cavity, promotion of axonal regeneration and sparing, and functional recovery with transplanted bone marrow stromal cell-derived Schwann cells after contusion injury to the adult rat spinal cord. J Neurosurg Spine 9:600-610.

118. Teng YD, EB Lavik, X Qu, KI Park, J Ourednik, D Zurakowski, R Langer and EY Snyder. (2002). Functional recovery following traumatic spinal cord injury mediated by a unique polymer scaffold seeded with neural stem cells. Proc Natl Acad Sci U S A 99:3024-3029.

119. Sykova E and P Jendelova. (2005). Magnetic resonance tracking of implanted adult and embryonic stem cells in injured brain and spinal cord. Ann N Y Acad Sci 1049:146160.

120. Zurita M and J Vaquero. (2006). Bone marrow stromal cells can achieve cure of chronic paraplegic rats: functional and morphological outcome one year after transplantation. Neurosci Lett 402:51-56.

121. Bakshi A, AL Barshinger, SA Swanger, V Madhavani, JS Shumsky, B Neuhuber and I Fischer. (2006). Lumbar puncture delivery of bone marrow stromal cells in spinal cord contusion: a novel method for minimally invasive cell transplantation. J Neurotrauma 23:55-65.

122. Crigler L, RC Robey, A Asawachaicharn, D Gaupp and DG Phinney. (2006). Human mesenchymal stem cell subpopulations express a variety of neuro-regulatory molecules and promote neuronal cell survival and neuritogenesis. Exp Neurol 198:54-64.

123. Bjorklund A and O Lindvall. (2000). Cell replacement therapies for central nervous system disorders. Nat Neurosci 3:537-544.

124. Alexander JK and PG Popovich. (2009). Neuroinflammation in spinal cord injury: therapeutic targets for neuroprotection and regeneration. Prog Brain Res 175:125-137.

125. Bartholdi D and ME Schwab. (1997). Expression of proinflammatory cytokine and chemokine mRNA upon experimental spinal cord injury in mouse: an in situ hybridization study. Eur J Neurosci 9:1422-1438. 
126. Streit WJ, SL Semple-Rowland, SD Hurley, RC Miller, PG Popovich and BT Stokes. (1998). Cytokine mRNA profiles in contused spinal cord and axotomized facial nucleus suggest a beneficial role for inflammation and gliosis. Exp Neurol 152:74-87.

127. Pierce GF, TA Mustoe, BW Altrock, TF Deuel and A Thomason. (1991). Role of platelet-derived growth factor in wound healing. J Cell Biochem 45:319-326.

128. Zhang SX, F Huang, M Gates, J White and EG Holmberg. (2010). Extensive scarring induced by chronic intrathecal tubing augmented cord tissue damage and worsened functional recovery after rat spinal cord injury. J Neurosci Methods 191:201-207.

129. Jones LL and MH Tuszynski. (2001). Chronic intrathecal infusions after spinal cord injury cause scarring and compression. Microsc Res Tech 54:317-324.

130. Rabchevsky AG and WJ Streit. (1998). Role of microglia in post injury repair and regeneration of the CNS. MRRD Res Rev 4:187-192.
Address correspondence to: Dr. Michael G. Fehlings

Division of Genetics and Development

Krembil Neuroscience Center

Toronto Western Research Institute

University Health Network

Toronto Western Hospital McLaughlin Pavilion

12th Floor Room 407

399 Bathurst Street

Toronto M5T 2S8

Canada

E-mail: michael.fehlings@uhn.on.ca

Received for publication October 20, 2011

Accepted after revision November 14, 2011

Prepublished on Liebert Instant Online November 15, 2011 